Aus der Poliklinik für Präventive Zahnmedizin, Parodontologie und Kariologie (Prof. Dr. med. dent. A. Wiegand)

im Zentrum für Zahn- Mund- und Kieferheilkunde

der Medizinischen Fakultät der Universität Göttingen

\title{
Nanopartikel und Ultraschall \\ als Hilfsmittel zur \\ Wurzelkanalreinigung
}

\author{
INAUGURAL-DISSERTATION \\ zur Erlangung des Doktorgrades \\ für Zahnheilkunde \\ der Medizinischen Fakultät der \\ Georg-August-Universität zu Göttingen
}

vorgelegt von

Christoph Beckmann

aus

Herford

Göttingen 2016 
Dekan:

Prof. Dr. rer. nat. H.K. Kroemer

\section{Betreuungsausschuss}

Betreuer/in

Prof. Dr. med. dent. M. Hülsmann

Ko-Betreuer/in:

Priv.-Doz. Dr. med. dent. M. Rödiger

\section{Prüfungskommission}

Referent/in

Ko-Referent/in:

Drittreferent/in:
Prof. Dr. med. dent. Michael Hülsmann

Priv.-Doz. Dr. med. dent. M. Rödiger

Datum der mündlichen Prüfung: 10.11.2016 
Hiermit erkläre ich, die Dissertation mit dem Titel "Nanopartikel und Ultraschall als Hilfsmittel zur Wurzelkanalreinigung" eigenständig angefertigt und keine anderen als die von mir angegebenen Quellen und Hilfsmittel verwendet zu haben.

Göttingen, den 27.7.2016 


\section{Inhaltsverzeichnis}

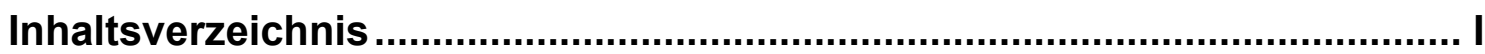

Abbildungsverzeichnis ............................................................................ III

Tabellenverzeichnis ..............................................................................

Abkürzungsverzeichnis.............................................................................

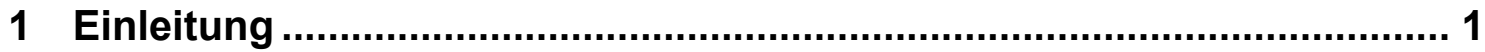

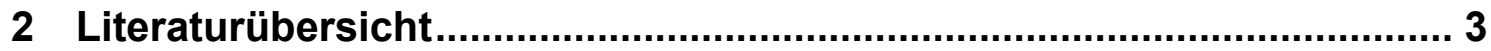

2.1 Desinfektion und Präparation des Wurzelkanalsystems ................................... 3

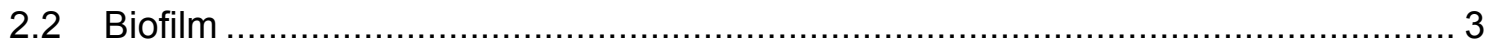

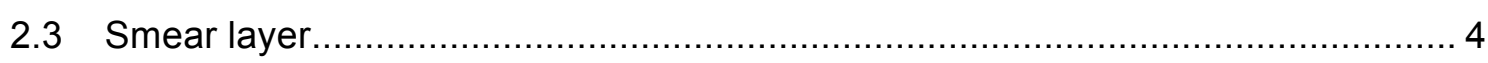

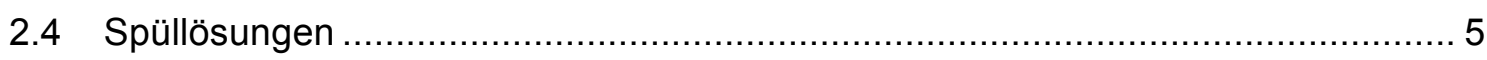

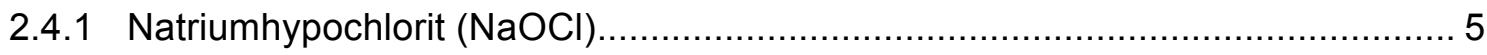

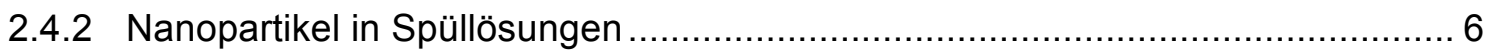

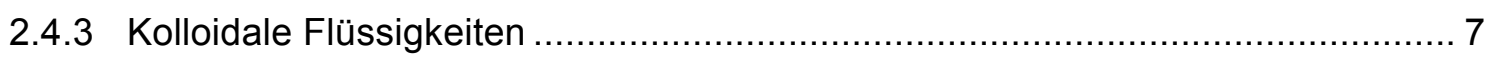

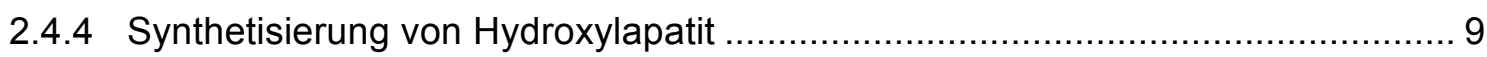

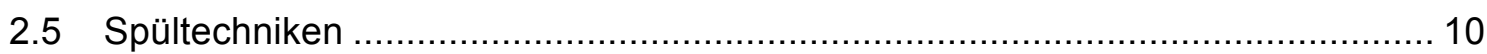

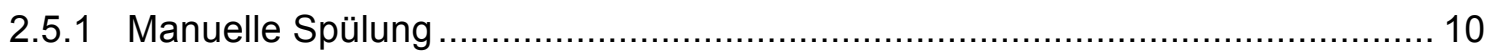

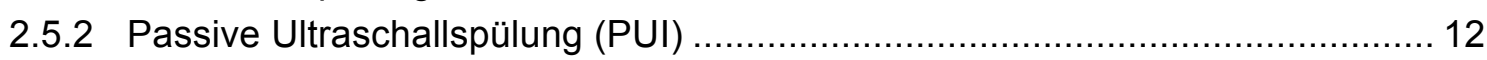

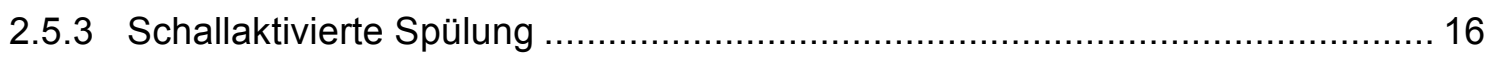

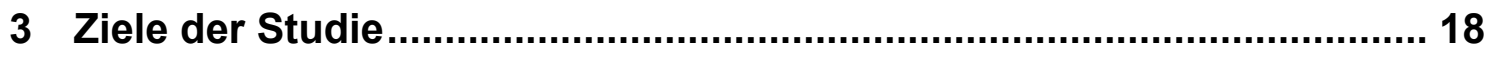

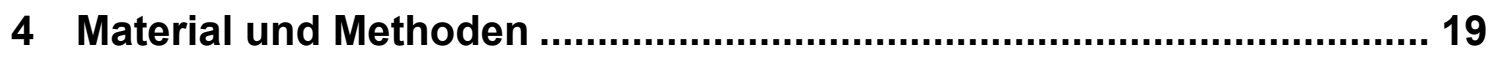

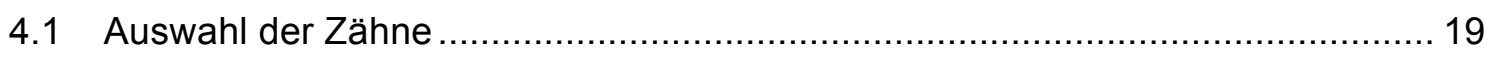

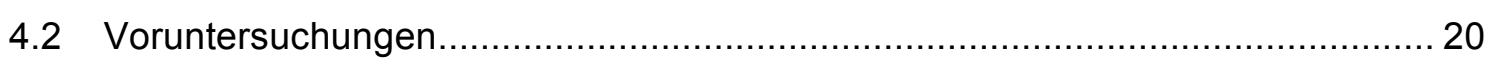

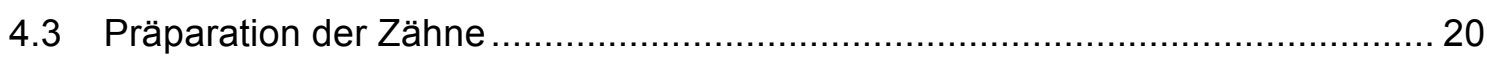

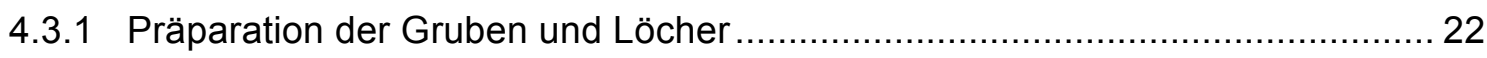

4.3.2 Fotografische Dokumentation der Versuchsreihen ...................................... 25

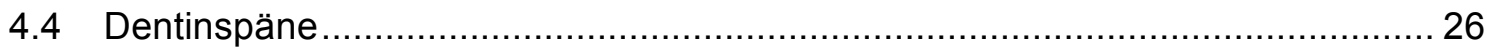

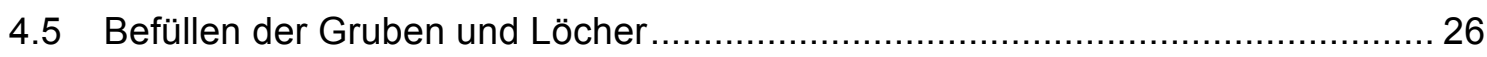

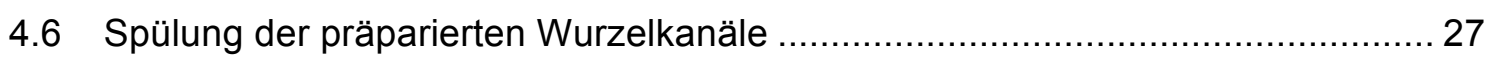

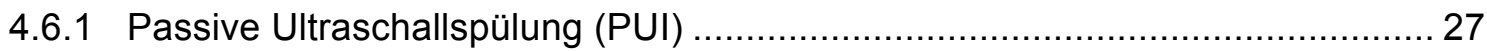

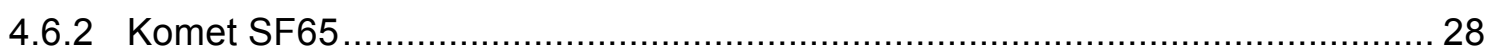

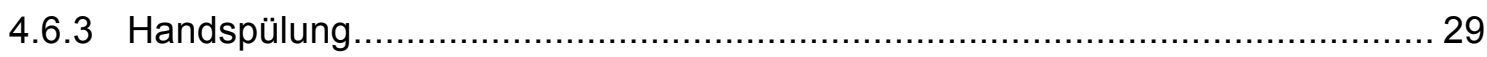

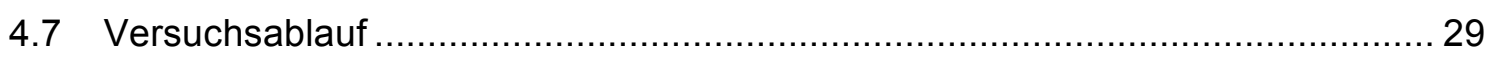

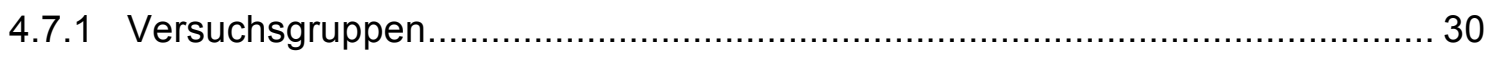




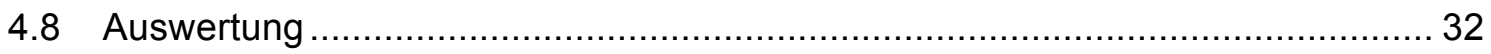

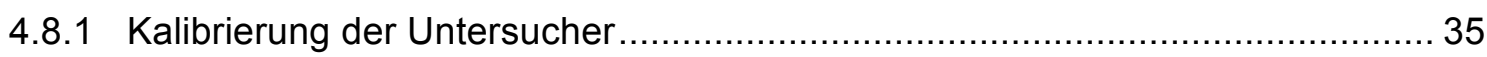

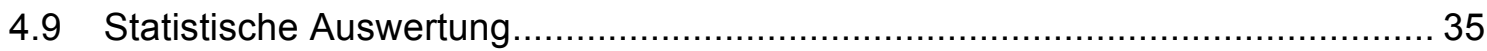

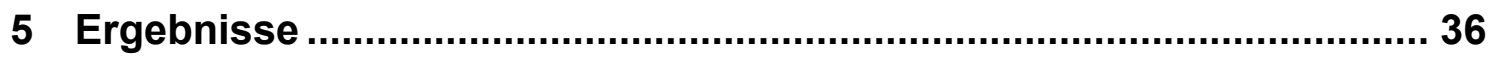

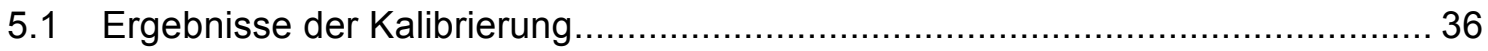

5.1.1 Interindividuelle Übereinstimmung und intraindividuelle Reproduzierbarkeit .... 36

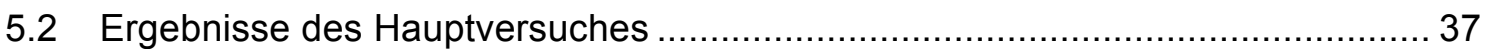

5.2.1 Die Vertiefungen in den Wurzelhälften ..................................................... 37

5.2.2 Differenzierung zwischen Spültechnik und Spülflüssigkeit ............................ 38

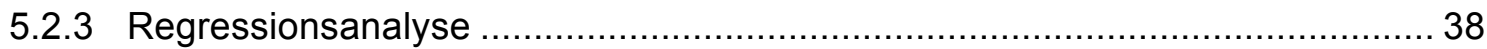

5.2.4 Absolute und relative Häufigkeitsverteilung ................................................. 39

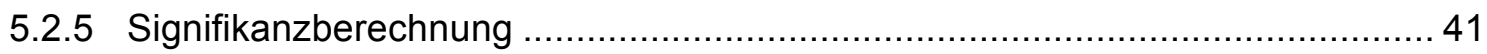

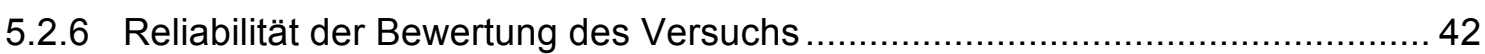

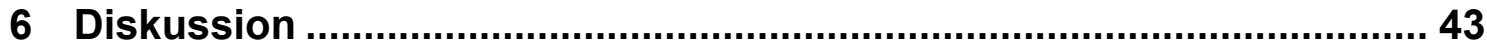

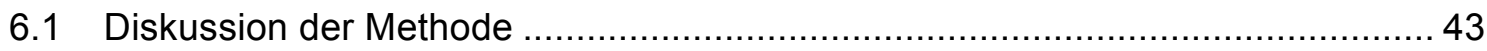

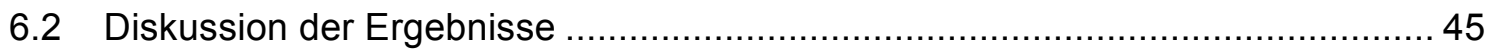

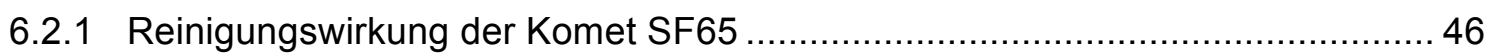

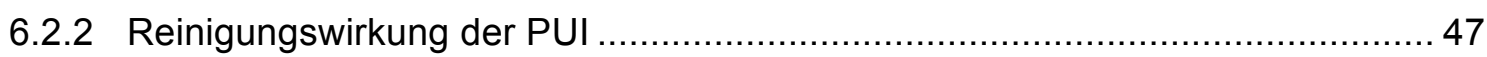

6.2.3 Reinigungswirkung der Handspülung ....................................................... 50

7 Zusammenfassung...................................................................... 52

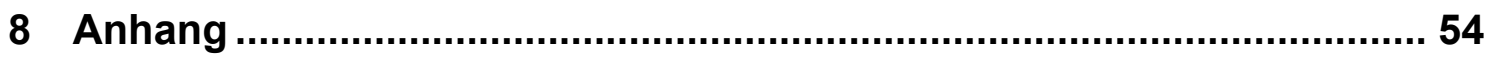

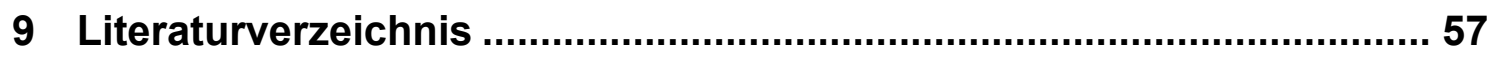

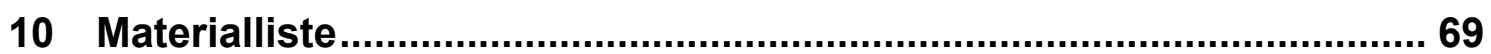




\section{Abbildungsverzeichnis}

Abbildung 1: Vector polish bei 5-facher Vergrößerung ….................................... 9

Abbildung 2: Vector polish bei 20-facher Vergrößerung ...................................... 9

Abbildung 3: Akustische Mikroströmungen entlang einer Feile in Wasser und als Schema (aus van der Sluis et al. 2007 S. 418)............................... 14

Abbildung 4: Montierter Zahn in der Silikonmasse............................................ 24

Abbildung 5: Modifizierung des Fingerspreaders mit einer Trennscheibe ............... 24

Abbildung 6: Präparation der Grube .......................................................... 24

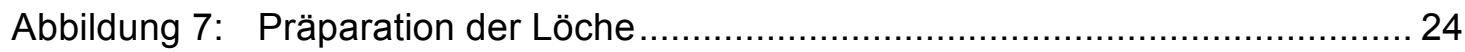

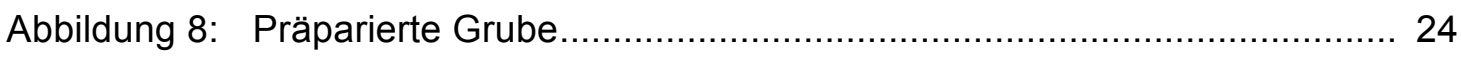

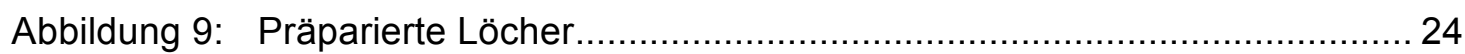

Abbildung 10: Position der Gruben und Löcher in den Zahnwurzelhälften ................. 25

Abbildung 11: Komet SF65 in Luft schwingend. Mit freundlicher Genehmigung der Fa. Brasseler.................................................................... 29

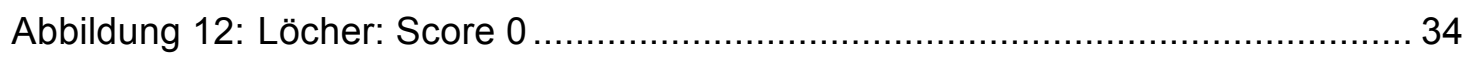

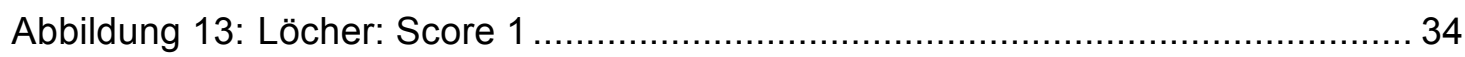

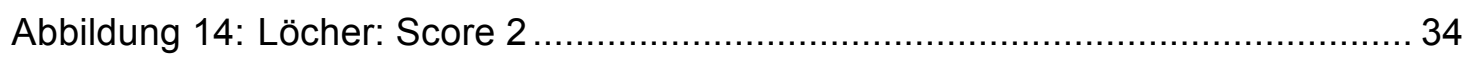

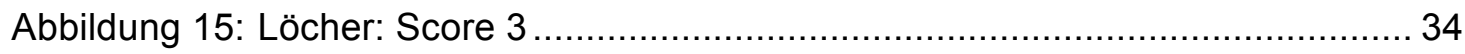

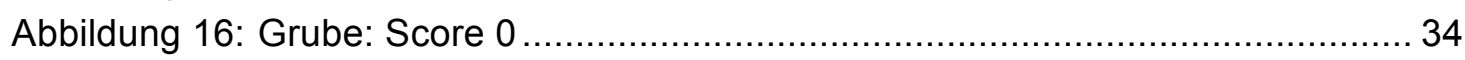

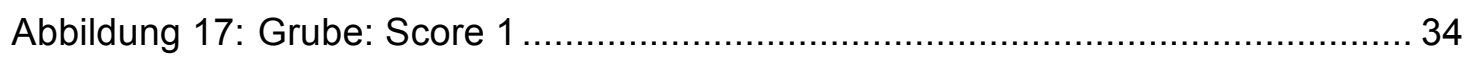

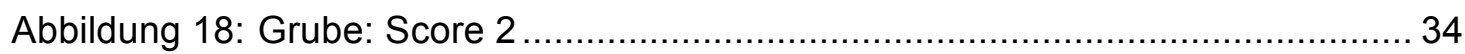

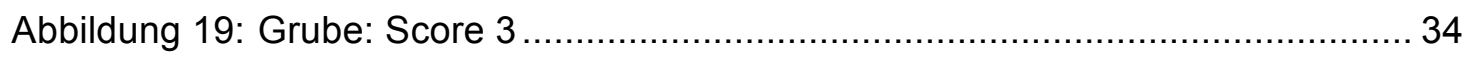

Abbildung 20: Intraindividuelle Übereinstimmung der Untersucher bei wiederholter Bewertung............................................................. 37

Abbildung 21: Übersicht über die von beiden Untersuchern vergebenen

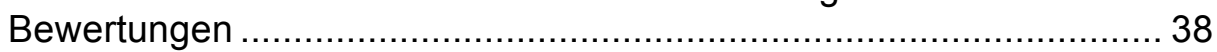

Abbildung 22: Relative Häufigkeit der Score-Verteilung in allen Gruppen .................. 39

Abbildung 23: Box Plot-Darstellung der verwendeten Spültechnik in Kombination mit den Spülflüssigkeiten. 


\section{Tabellenverzeichnis}

Tabelle 1: $\quad$ Absolute Häufigkeit der Score-Verteilung für alle Gruppen................. 39

Tabelle 2: $\quad$ Signifikanzen in den Unterschieden zwischen den einzelnen

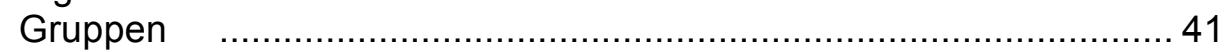

Tabelle 3: Intraindividuelle Reproduzierbarkeit der Bewertungen der beiden Untersucher........................................................................ 42

Tabelle 4: $\quad$ Übersicht über die vergebenen Score-Werte ...................................... 55

Tabelle 5: $\quad$ Regressionstabelle: Komet SF65 $=1, \mathrm{PUI}=2$, Handspülung $=3$, Nanopartikel $=1, \mathrm{NaOCl}=2$, Gruben $=1$, Löcher $=2 \ldots \ldots \ldots \ldots \ldots \ldots \ldots . . .56$

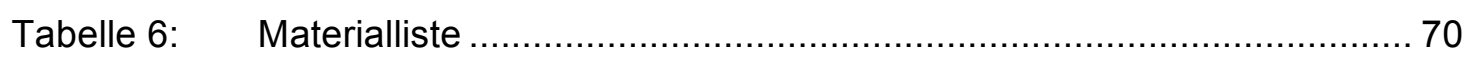




\title{
Abkürzungsverzeichnis
}

\author{
EDTA Ethylendiamintetraessigsäure \\ $\mathrm{NaOCl}$ Natriumhypochlorit \\ PUI Passive Ultrasonic Irrigation \\ CUI Continuous Ultrasonic Irrigation
}




\section{Einleitung}

Kommt es als Folge von Karies zur Entzündung und später zur Nekrose der Pulpa, im fortgeschrittenen Fall mit Entwicklung einer apikalen Parodontitis, so stellt meistens die Wurzelkanalbehandlung den adäquaten Versuch dar, den erkrankten Zahn zu erhalten und eine Extraktion zu vermeiden. Während einer Wurzelkanalbehandlung soll das infizierte und nekrotische Gewebe möglichst umfassend entfernt und der gereinigte Wurzelkanal durch eine möglichst dichte und wandständige Wurzelkanalfüllung dauerhaft verschlossen werden. Im Verlauf der Wurzelkanalbehandlung stellen sich für den Zahnarzt die Herausforderungen, ein breit gefächertes Keimspektrum zu beseitigen und einen schmerzfreien Zustand für den Patienten herzustellen. Die hierfür grundlegende Desinfektion des Wurzelkanalsystems besteht aus einem gut abgestimmten, standardisierten Verfahren aus instrumenteller und chemischer Bearbeitung des komplexen endodontischen Hohlraumsystems. Die unterschiedlichen anatomischen Formvarianten des Wurzelkanalsystems erschweren die mechanische Bearbeitung.

Die maschinelle Präparation des Wurzelkanalsystems ermöglicht es verschiedenen Agenzien, in nicht instrumentierte Bereiche einzudringen und dort zu wirken. Dieses Zusammenspiel der chemo-mechanischen Desinfektion des Wurzelkanals bildet die Basis für eine erfolgreiche endodontische Therapie eines Zahnes (Friedman 2002). Es können dabei Erfolgsquoten von $86 \%$ bis 93\% erreicht werden ( $\mathrm{Ng}$ et al. 2010).

Es stellt sich die Frage, welche Möglichkeiten es gibt, diese Erfolgsquote zu verbessern. Durch Einsatz der Nanotechnologie könnte es möglich sein, dieses fein abgestimmte Therapiekonzept der Wurzelkanalbehandlung zu verbessern. Da jedoch Nanotechnologie ein noch sehr unerforschtes Feld in der Zahnmedizin ist, bietet es sich an, den Einsatz von Nanopartikeln in der Endodontie kritisch zu überprüfen.

Da Spüllösungen alleine nicht die Möglichkeit haben, das Wurzelkanalsystem ausreichend zu säubern, wird intensiv an der Aktivierung von Spülflüssigkeiten gearbeitet. 
In der vorliegenden Arbeit wird untersucht, welchen Einfluss Nanopartikel auf die Reinigungswirkung bei einer Wurzelkanalbehandlung haben. Die Nanopartikel wurden hierbei in einwurzeligen Zähnen mit Schall- und Ultraschallspitzen aktiviert. 


\section{Literaturübersicht}

\subsection{Desinfektion und Präparation des Wurzelkanalsystems}

\subsection{Biofilm}

Der Begriff des Biofilmes beschreibt eine Schicht aus Bakterien, Pilzen, Protozoen oder ähnlichen Mikroorganismen, die sich organisieren, um widerstandsfähiger gegen äußere Bedrohungen zu sein (Svensäter und Bergenholtz 2004). Der Biofilm ist wesentlich pathogener als Bakterienformationen in einer planktonisch organisierten Phase (Svensäter und Bergenholtz 2004). Diese Organisation von Bakterien in dem endodontischen System in Form eines Biofilms ist vermutlich verantwortlich für die therapieresistente apikale Parodontitis (Ferreira et al. 2004), sodass die Entfernung dieses Biofilmes notwendig ist (Haapasalo et al. 2005). Die Entstehung des Biofilmes folgt anscheinend einem klassischen Werdegang: Adhäsion, Kolonisierung der planktonischen Mikroorganismen auf einer festen Oberfläche und darauf folgend die Freisetzung von Mikroorganismen in die Umgebung, die sich wiederum an anderen Stellen als neuer Biofilm organisieren können. Dabei werden Proteine und Glykoproteine aus dem Speichel entnommen und dienen als Nährboden und Matrix des späteren Biofilmes. Alleine die Anzahl der Mikroorganismen im Status der planktonischen Phase beträgt zwischen zehn bis hundert Millionen pro Milliliter Kanalinhalt. Dabei lassen sich vor allem Streptococcus gordonii, Streptococcus mitis, Porphyromonas gingivalis, Fusubakterium nucleatum und Prevotella intermedia im endodontischen Biofilm feststellen, die auch durch Quorum sensing untereinander kommunizieren (Svensäter und Bergenholtz 2004; Peciuliene et al. 2008). Allerdings sind auch verschiedene andere Formen von Kokken, Stäbchen, Spirochäten und Spirillen in diesem Biofilm zu finden (Nair 1987). Diese sind selbstaggregierend und ähneln in der anfänglichen Entstehung plaquebildenden Organismen, ähnlich denen auf Oberflächen von Zähnen. Besonders ist dabei der apikale Bereich eines Wurzelkanals betroffen, in dem 
sich viele Nischen befinden, in denen sich die Mikroorganismen in maiskolbenartigen Strukturen ansiedeln können (Molven et al. 1991).

Es wurde versucht, den Biofilm durch verschiedene Spülflüssigkeiten zu zerstören. Dabei zeigte sich, dass $\mathrm{NaOCl}$ (Natriumhypochlorit) den größten Effekt auf die Bakterienkolonien hatte (Briseno et al. 1992; Spratt et al. 2001). Die Spültechnik hat jedoch einen ebenso großen Effekt auf die Beseitigung des Biofilms wie die Art der Spülflüssigkeit (Cunningham et al. 1982; Halford et al. 2012; Cachovan et al. 2013; Neelakantan et al. 2015).

\subsection{Smear layer}

Sobald Dentin durch Handinstrumente oder rotierende Instrumente angeschliffen wird, entsteht eine Schmierschicht. Dieser smear layer besteht sowohl aus organischen als auch anorganischen Bestandteilen in einer Schichtstärke von 1 bis $5 \mu$ m (Brännström und Johnson 1974; Mader et al. 1984). Die einzelnen Partikel variieren in ihrer Größe zwischen 0,05 - 0,1 $\mu \mathrm{m}$ (Pashley et al. 1988).

Zuerst wurde diese Schicht im instrumentierten Wurzelkanal von McComb und Smith im Jahr 1975 beschrieben (McComb und Smith 1975). Es lassen sich Dentinspäne, Prädentin, Gewebereste der Pulpa, Odontoblasten, denaturiertes Kollagen, Spülflüssigkeitsreste und im Falle von infizierten Wurzelkanälen auch Bakterien, Toxine und Abbauprodukte von Bakterien in dem smear layer nachweisen (McComb und Smith 1975). Unter dem Rasterelektronenmikroskop sind amorphe und irregulär geformte Partikel zu erkennen (Yamada et al. 1983).

Bei der Präparation entsteht sowohl eine oberflächliche Schmierschicht als auch Debris, der bis zu $40 \mu \mathrm{m}$ Tiefe in die Dentintubuli eindringen (Mader et al. 1984) und dort sogenannte smear plugs bilden kann. Cengiz et al. vermuteten, dass diese durch Kapillarkräfte zwischen den Dentintubuli und dem Material entstehen (Cengiz et al. 1990). Vermutlich sind diese Kapillarkräfte auch dafür verantwortlich, dass die smear plugs in einer Tiefe von bis zu $110 \mu \mathrm{m}$ in den Dentintubuli nachgewiesen wurden (Aktener et al. 1989).

Es besteht aber keine Einigkeit darüber, ob der smear layer entfernt werden sollte oder nicht. Gegen die Entfernung spricht, dass der smear layer die 
Dentintubuli verstopft und so wie ein Flüssigkeitsfilter funktioniert, der ein Fortschreiten der Bakterieninvasion verhindert (Michelich et al. 1980; Pashley et al. 1981).

Dem gegenüber sprechen eine Reihe von Argumenten für die Entfernung der Schmierschicht: Die antimikrobielle Wirkung medikamentöser Einlagen kann verzögert oder gar gänzlich verhindert werden, wenn die Schmierschicht nicht entfernt wird (Yamada et al. 1983; Ørstavik und Haapasalo 1990; Drake et al. 1994). In der Schmierschicht selbst können Bakterien noch weiter überleben und weitere Bereiche infiltrieren (Baker et al. 1975; Yamada et al. 1983). Die Verbindung eines Wurzelkanalsealers als Teil einer Wurzelkanalfüllung mit der inneren Wurzeldentinwand verschlechtert sich durch eine nicht entfernte Schmierschicht, sodass ein koronales leakage entsteht (Taylor et al. 1997). Es kann auch vermutet werden, dass die Schmierschicht die Desinfektion des Dentins durch $\mathrm{NaOCl}$ verhindert (Violich und Chandler 2010).

Eine einheitliche Dentinoberfläche mit geöffneten Dentintubuli ist anzustreben, um eine saubere Oberfläche des Wurzeldentins nach Präparation und Desinfektion zu erzielen (Gulabivala et al. 2005). Daher sollte die Schmierschicht komplett entfernt werden.

\subsection{Spüllösungen}

\subsubsection{Natriumhypochlorit (NaOCl)}

Natriumhypochlorit ist die am häufigsten verwendete Spülflüssigkeit in der Endodontie, da sie ein breites Indikationsfeld abdeckt. In der Literatur werden sowohl die antibakterielle Wirksamkeit als auch die Fähigkeit beschrieben, vitales und auch nekrotisches Gewebe aufzulösen (Haapasalo et al. 2005). Die positiven Eigenschaften von $\mathrm{NaOCl}$ werden durch eine Aktivierung der Flüssigkeit verstärkt, sodass sich viele Studien mit unterschiedlichen aktivierten Spültechniken beschäftigten (Rödig et al. 2010a; Arslan et al. 2014; Mohammadi et al. 2015). Diese In-vitro-Studien wurden überwiegend an extrahierten Zähnen durchgeführt und lieferten für aktiviertes $\mathrm{NaOCl}$ vielversprechende Ergebnisse. 
Klassischerweise wird Natriumhypochlorit mit einer Spülkanüle in den Wurzelkanal eingebracht. Ein Volumen von ungefähr $2 \mathrm{ml}$ Spülflüssigkeit sollte durch eine stumpfe, apikal offene Kanüle transportiert werden. In den letzten Jahren drängten jedoch eine Vielzahl an Varianten des Transportes und der Aktivierung von $\mathrm{NaOCl}$ auf den dentalen Markt. Dabei erwiesen sich vor allem die schall- und die ultraschallaktivierte $\mathrm{NaOCl}$-Spülung als vielversprechend. Mehrere Studien zeigten, dass eine passive Ultraschallaktivierung sauberere Wurzelkanäle hinterlässt als die passive, nicht aktivierte Handspülung (Sabins et al. 2003; Jiang et al. 2010b; Rödig et al. 2010a; Paqué et al. 2011; SáinzPardo et al. 2014).

\subsubsection{Nanopartikel in Spüllösungen}

Nanopartikel treten in den letzten Jahren zunehmend in den Fokus der medizinischen Forschung. Auch in der Zahnmedizin wird von einem Teilgebiet der Nanodentistry gesprochen (Samiei et al. 2016). Als Nanopartikel gelten Verbindungen in einer Größenordnung von 1 bis ca. $100 \mathrm{~nm}$ - also $10^{-9} \mathrm{~m}$. Dabei sind besonders Nanopartikel in den Blickwinkel getreten, die antimikrobielle Eigenschaften besitzen, um so eine verbesserte Wurzelkanaldesinfektion zu erzielen. Bisher wurden sowohl metallische Nanopartikel, polymere Nanopartikel als auch bioaktive, nicht organische Nanopartikel untersucht.

Unter den metallischen Nanopartikeln wurden vorwiegend Silberpartikel aufgrund der bereits bekannten antibakteriellen Eigenschaften des Silbers untersucht. Sowohl als Spülgel, Spülflüssigkeit als auch medikamentöse Einlage zeigten silberhaltige Nanopartikel gegenüber $E$. faecalis im Vergleich zu Chlorhexidin und Natriumhypochlorit zwar zufriedenstellende Ergebnisse, überwiegend wird aber die Verwendung von Silberpartikeln als medikamentöse Zwischeneinlage empfohlen und nicht als Spülflüssigkeit (Wu et al. 2014; Samiei et al. 2016). Darüber hinaus wurden auch Zinkoxid-beladene Nanopartikel und Chitosan-Nanopartikel auf deren Wirkungsweise auf Dentin untersucht. Mit diesen Nanopartikeln behandelte Dentinoberflächen zeigten eine deutlich geringere Anheftungsmöglichkeit für Bakterien als unbehandelte Oberflächen (Kishen et al. 2008). Auch wenn weitere Studien zum bakteriellen Wachstum gleichgute Ergebnisse von Silberpartikeln als Spüllösung im 
Vergleich zu konventionell eingesetztem $\mathrm{NaOCl}$ zeigten, sind sich die Untersucher einig, dass weitere Studien folgen müssen (Moghadas et al. 2012).

Die polymerischen Nanopartikel zeigten deutliche Effekte gegen Bakterien unter Verwendung der fotodynamischen Therapie in Kombination mit einem Natriumsalz (,Rose Bengal') verbunden mit Chitosan (Shrestha und Kishen 2014). In einer vorhergehenden Studie zeigte die selbe Forschungsgruppe um Shrestha et al., dass Nanopartikel bei Ultraschallaktivierung von kollabierenden Mikrobläschen bis zu $1000 \mu \mathrm{m}$ tief in Dentintubuli hineinbefördert werden können (Shrestha et al. 2009).

Hingegen erwiesen sich die Komponenten der Studien über bioaktives Glas und Nanopulver als nur teilweise nutzbar für endodontische Therapiemöglichkeiten (Mortazavi et al. 2010). Auch Wu et al. (2012) sahen die Möglichkeit, mit Nanopartikeln antibiotisch wirksame Substanzen zu transportieren und somit die knochenassoziierte Genexpression im parodontalen Ligament zu fördern. Bei gut abgestimmten Konzentrationen werden Vorteile gegenüber konventionellen $\mathrm{Ca}(\mathrm{OH})_{2}$-Präparaten beschrieben (Wu et al. 2012).

Diese vorliegenden In-vitro-Studien zeigen allesamt, dass es für jeweils spezielle Nanopartikel Anwendungsgebiete in der Zahnmedizin geben könnte, ihr Einsatz jedoch streng einzugrenzen ist. Noch ist nicht klar, welche unvorhergesehenen Nebenwirkungen Nanopartikel für den menschlichen Körper haben können. Sowohl die Umwelt als auch zelluläre Systeme können nachteilig durch Apoptose, vermindertes Zellwachstum, Gentoxizität, respiratorische und neurologische Schäden beeinflusst werden (Samiei et al. 2016).

\subsubsection{Kolloidale Flüssigkeiten}

Kolloide sind feste Bestandteile, die in Flüssigkeiten gleichmäßig verteilt sind, welche daher als kolloidale Flüssigkeiten bezeichnet werden. Diese gelten als Dispersionslösungen und besitzen besondere chemische Eigenschaften: Es finden sich keine Gefrierpunkterniedrigung und Siedepunkterhöhung und es lässt sich kein osmotischer Druck feststellen. In den Flüssigkeiten sind kleine Nanopartikel im Größenbereich von ca. $10^{-3}$ bis $10^{-6} \mathrm{~mm}$ gelöst. Durch Sedimentation trennen sich die Bestandteile nach Gewicht und Dichte. Das 
Verhalten kolloidaler Flüssigkeiten weicht vom Newtonschen Gesetz ab, ihr laminarer Fließvorgang ist nicht mehr proportional zur Schergeschwindigkeit:

$$
\tau=\eta * \dot{\gamma}
$$

$\tau$ : Scherspannung; $\eta$ : dynamische Viskosität (konst.); $\dot{\gamma}$ : Schergeschwindigkeit

Die Hypothese, dass ein effizienter Materialabtrag durch Nanopartikel im endodontischen System stattfindet, ohne dabei die Wurzelkanalgeometrie nachhaltig zu verschlechtern, beruht auf der Erkenntnis, dass sich in der Parodontologie subgingivale Konkremente entfernen lassen, ohne dabei Defekte in der Zementoberfläche zu verursachen. Dabei werden bei einer Amplitude von $30 \mu \mathrm{m}$ mit einem Küretten- oder Metallspitzenaufsatz gleichzeitig entweder Hydroxylapatit- oder Silikoncarbidpartikel zur Entfernung der Konkremente verwendet (Dürr Dental). Die Kombination von Ultraschall bei einer Frequenz von $25 \mathrm{kHz}$ und der Verwendung solcher Nanopartikel scheint dabei ähnlich effizient zu wirken wie ein konventionelles Ultraschallsystem (Braun et al. 2005). Als Nebeneffekt ließ sich zudem feststellen, dass das subjektive Schmerzempfinden von Patienten erheblich reduziert ist, was sich auf die ausschließlich horizontale Ultraschallbewegung des systemeigenen Vector-Ultraschallsystems zurückführen lässt (Braun et al. 2003).

Ebenfalls wird davon ausgegangen, dass die erzeugten Mikroströmungen wie bei dem Ultraschallscaling einen hydrodynamischen Effekt verursachen, der durch Kavitation die Effizienz steigert (Khambay und Walmsley 1999).

Braun et al. (2003) gingen davon aus, dass die durch die Ultraschallwellen vermittelte Energie durch die Nanopartikel direkter übertragen wird. Es sind zwei kolloidale Flüssigkeiten des Vector-Systems auf dem Markt verfügbar. Das Vector polish fluid verfügt dabei über Hydroxylapatit-Partikel einer Größe von $<10 \mu \mathrm{m}$, das Vector abrasive fluid beinhaltet Hydroxylapatit-Partikel von ungefähr $50 \mu \mathrm{m}$ Größe.

Die Ergebnisse rasterelektronenmikroskopischer Studien erlauben den Schluss, dass nach einer Therapie mit dem Vector-System in Verbindung mit Vector polish fluid eine glatte Wurzeloberfläche mit Erhaltung von mehr Zahnzement 
als bei anderen vergleichbaren Systemen $\mathrm{zu}$ erreichen ist. In den rasterelektronenmikroskopischen Bildern behandelter Zähne wird eine Oberfläche ähnlich der von gesunden Zahnwurzeln sichtbar (Kishida et al. 2004) .
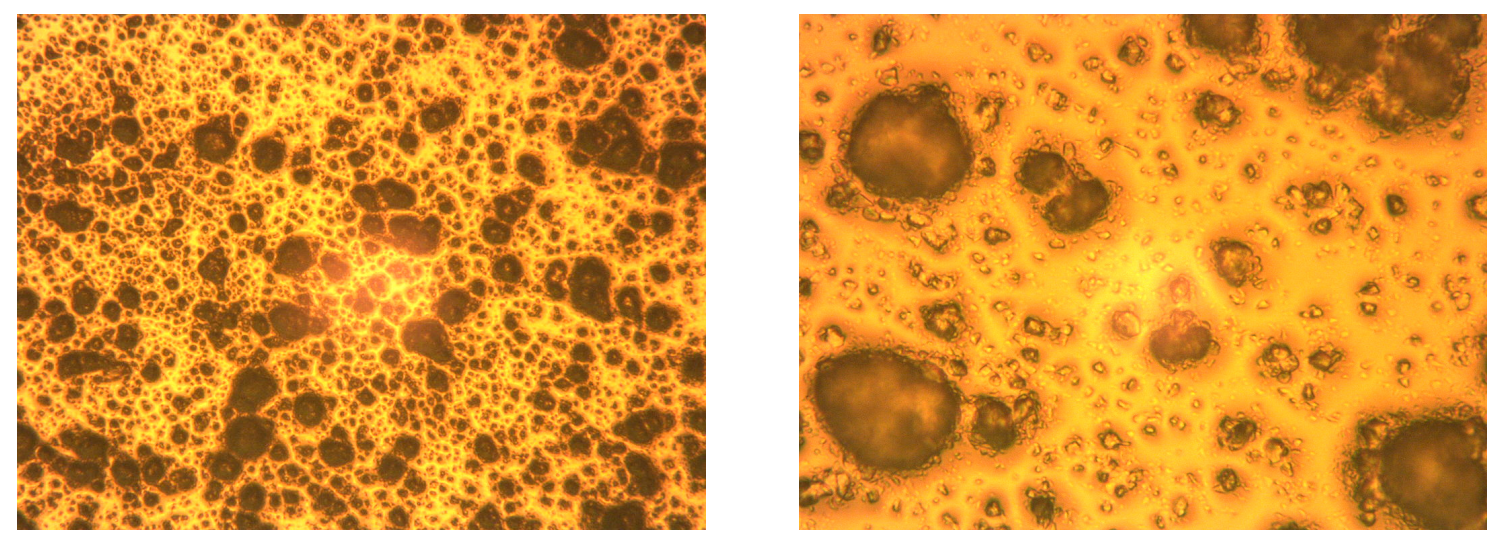

Abbildung 1: Vector polish bei 5-facher Vergrößerung

Abbildung 2: Vector polish bei 20-facher Vergrößerung

\subsubsection{Synthetisierung von Hydroxylapatit}

Künstliches Hydroxylapatit wird in einem sogenannten „Bottom-up“ Verfahren hergestellt, das heißt einer Synthese und Selbstorganisation von Molekülen (BASF AG 2002).

Das synthetische Hydroxylapatit wird aus der Reaktion von Kalziumazetat und 85\%iger Phosphorsäure gewonnen. Es kann auch Essigsäure hinzugesetzt werden. Anschließend wird das Gemisch auf eine Temperatur zwischen 40 und $100{ }^{\circ} \mathrm{C}$ erhitzt und danach gefriergetrocknet. Je nach zugeführter Hitze entstehen größere, flache und plattenartige Hydroxylapatitkristalle oder kleinere Stäbchenkristalle. Im weiteren Verarbeitungsprozess können die Stäbchenkristalle durch spark plasma sintering verdichtet werden, um so die endgültige Größe der Nanopartikel festzulegen (Kumar et al. 2005).

Das synthetisch hergestellte Hydroxylapatit des Vector polish fluid bewegt sich in der Größenordnung von Nanopartikeln und Mikropartikeln und unterliegt prozessbedingten Schwankungen. 


\subsection{Spültechniken}

\subsubsection{Manuelle Spülung}

Die rein mechanische Präparation des Wurzelkanalsystems führt nicht zu einer ausreichenden Reduktion der Mikroorganismen, sodass während der Wurzelkanalbehandlung eine chemo-mechanische Präparation notwendig ist (DGZMK 2006). Entscheidend ist die Säuberung des gesamten endodontischen Systems mit besonderem Augenmerk auf das apikale Drittel (Abou-Rass und Piccinino 1982; Rollison et al. 2002).

Die Wurzelkanalspülung mit Hilfe einer Handspritze stellt die einfachste Form der Wurzelkanalspülung in der Endodontie dar. Gleichzeitig ist sie die am weitesten verbreitete Methode, um die unterschiedlichen Spülflüssigkeiten in das Wurzelkanallumen zu applizieren (van der Sluis et al. 2006a).

Spülkanülen sind in unterschiedlichen Größen von 0,23 bis $0,4 \mathrm{~mm}$ erhältlich und in unterschiedlichem Design konstruiert. Es gibt Kanülen mit seitlichen und apikalen Öffnungen. Je kleiner der Durchmesser der Spülkanüle ist, desto eher können diese frakturieren oder mit $\mathrm{NaOCl}$ Kristallen verstopft werden (Moser und Heuer 1982), obwohl sie höhere Spüldrücke erzeugen.

Das Überpressen von Spülflüssigkeit in das periapikale Gewebe ist ein Problem, das noch am ehesten mit der Handspülung kontrolliert und somit vermieden werden kann (Boutsioukis et al. 2010b). Bei seitlich geöffneten Spülkanülen ist die Gefahr der apikalen Flüssigkeitsextrusion zwar geringer, aber sie erzeugen einen geringeren Druck und eine reduzierte Reichweite des Flüssigkeitsmediums. Bei einer Präparation des Wurzelkanals bis zur ISOGröße 55 war auch der Flüssigkeitsaustausch zu gering, sodass die Spülkanülen auf $1 \mathrm{~mm}$ vor Arbeitslänge eingebracht werden mussten (Boutsioukis et al. 2010a).

Es ist möglich, die Kanüle in den Wurzelkanal einzubringen und während des Spülvorganges dort auf einer bestimmten Arbeitslänge zu belassen oder die Spülkanüle aktiv und ohne Friktion auf und ab zu bewegen (Moser und Heuer 1982). Aus dem Verklemmen der Kanüle können schwere Folgen resultieren (Kahn et al. 1995). Moser und Heuer (1982) beobachteten, dass eine aktive 
Auf- und Abbewegung Vorteile bietet, damit sich kein Debris apikal im Kanal festsetzen kann.

Bereits im Jahre 1977 befasste sich Ram mit dem Präparationsdurchmesser sowie den bei der Spülung notwendigen Drücken, die entscheiden, wie weit die Spülflüssigkeit aus der Kanüle austritt (Ram 1977). Er kam zu dem Schluss, dass bei einwurzeligen Zähnen mindestens eine Präparationsgröße von ISO 40 notwendig ist, um eine ausreichende Beseitigung des Debris zu gewährleisten. Wurde der Spüldruck verdoppelt, trat zwar mehr Spülflüssigkeit aus der Kanüle aus, allerdings konnte kein Unterschied bei der Entfernung von radiopaquem Material festgestellt werden. Neuere Studien kommen ebenfalls zu dem Ergebnis, dass die apikale Präparationsgröße einen wesentlichen Faktor für eine erfolgreiche Entfernung von pulpalem Gewebe und infiziertem Dentin darstellt (Wu und Wesselink 1995; Khademi et al. 2006; Hsieh et al. 2007; Boutsioukis et al. 2010a). Allerdings befürchteten Hsieh et al. (2007), dass ab einer Präparationsgröße von ISO 80 Turbulenzen bei der Spülung einen negativen Einfluss auf das Debridement haben könnten. Falk und Sedgley (2005) berichteten, dass es keinen Unterschied in der Reinigungswirkung zwischen einer Präparationsgröße 60 oder 77 gab, allerdings bei einer Präparationsgröße ISO 36 die Bakterienreduktion nicht zufrieden stellend ausfiel. Khademi et al. (2006) forderten hingegen eine Präparation bis mindestens zur Größe 30/.06.

Boutsioukis et al. (2010b) beschrieben, dass die Konizität der Präparation entscheidend zu der Erneuerung der Spülflüssigkeit beiträgt und das Risiko apikaler Extrusion verringert.

Eine vorsichtige Applikation der Spülflüssigkeit auf $1 \mathrm{~mm}$ koronal der Arbeitslänge garantiert eine ausreichende Reinigung (Sedgley et al. 2005). Ein Problem stellt allerdings der sogenannte Vapor-Lock-Effekt dar. Dieser beschreibt die Problematik, dass sich Luft vor den inserierten Spülflüssigkeiten herschieben lässt und somit apikale Kanalbereiche aufgrund dieser am tiefsten apikalen Punkt befindlichen Luftblase nicht von Spülflüssigkeit erreicht werden können ( $\mathrm{Gu}$ et al. 2009). Gu et al. (2009) beziehen dies sowohl auf den Hauptkanal als auch auf die kleinen Seitenkanälchen, die womöglich nie mit dem Spülmedium in Kontakt kommen. Auch Tay et al. (2010) sahen dieses 
Problem und beobachteten das Verhalten der eingeschlossenen Luft in apikal offenen und geschlossenen Wurzelkanalmodellen. Sie beobachteten, dass der Vapor-Lock-Effekt einen maßgeblichen Einfluss auf die Reinigungseffektivität hat. Die Studien von de Gregorio et al. (2010) zeigen, dass die klassische Handspülung sowohl bei der Penetration lateraler Kanäle als auch dem Erreichen der Arbeitslänge anderen Spültechniken signifikant unterlegen ist.

Es kann zusammengefasst werden, dass eine Spülkanüle der Größe 30 Gauge, also mit einem Außendurchmesser von 0,3 mm (Chow 1983; Kahn et al. 1995), eine angemessene Präparationsgröße (Boutsioukis et al. 2010a), ein großer Taper (Boutsioukis et al. 2010b), hochvolumige Spülungen nach jedem Präparationsinstrument sowie eine Insertionstiefe von $1 \mathrm{~mm}$ koronal der Arbeitslänge (Sedgley et al. 2004; Sedgley et al. 2005) notwendig und ausreichend sind, um ein erfolgreiches Debridement im Hauptkanal der komplexen Wurzelkanalanatomie zu gewährleisten. Die Spülflüssigkeit muss mit der Spülkanüle nah an das zu entfernende Material herangeführt werden, um dies zu beseitigen (Abou-Rass und Piccinino 1982) und sollte dabei vertikal bewegt werden (Moser und Heuer 1982). Die Generation ausreichender Scherkräfte, die eine Abtrennung von Debris und Biofilm von der Wurzelkanalwand ermöglichen, ist nur durch eine ausgewogene Kombination dieser Parameter zu erreichen. So ist eine Reduktion der Bakterien auf 10\% der Ausgangspopulation möglich (Falk und Sedgley 2005), aber diese ist nicht gänzlich vorhersagbar (Card et al. 2002).

\subsubsection{Passive Ultraschallspülung (PUI)}

Der Einsatz von Ultraschallgeräten in der Endodontie wurde zuerst von Richman (1957) dokumentiert. Zu unterscheiden ist jedoch, ob es sich dabei um eine Spülung mit einer gleichzeitigen Instrumentierung handelt oder aber um eine Spülung ohne Instrumentierung und ohne mechanische Veränderung des Wurzelkanalsystems.

Es hat sich erwiesen, dass die gleichzeitige Spülung während der Instrumentierung weniger effektiv ist (Weller et al. 1980; van der Sluis et al. 2007a). Diese Ultraschallinstrumentierung würde zu einem unkontrollierten Substanz- 
abtrag mit unvorhersehbaren Folgen wie Perforationen, Stufenbildung, ungewollter Überinstrumentierung oder apikalen Erweiterungen („Zips“ und „Elbows“) führen.

Während Schallspülungen mit Frequenzen zwischen 1000 bis $6000 \mathrm{~Hz}$ arbeiten, liefert die Ultraschallspülung Arbeitsfrequenzen um die $40 \mathrm{kHz}$. Da jedoch die auftretenden Strömungen in direkter Abhängigkeit zur Strömungsgeschwindigkeit stehen, die wiederum maßgeblich von der Frequenz und Amplitude des Drahtes abhängig ist, ist es nicht verwunderlich, dass die passive Ultraschallspülung der Schallspülung signifikant überlegen ist (Sabins et al. 2003).

$$
v=\frac{\omega \varepsilon_{0}^{2}}{a}
$$

v: Strömungsgeschwindigkeit der Flüssigkeit; $\omega: 2 \pi^{*} \mathrm{~Hz}$; a: Radius des Drahtes; $\varepsilon_{0}$ : Amplitude des Drahtes

Der Begriff der passiven Ultraschallspülung wurde zuerst von Weller im Jahr 1980 erwähnt. Die Spülspitzen bestehen meistens aus einer dünnen Feile oder einem weichen Draht der ISO-Größen 10-20. Größere Instrumente ab ISO Größe 25 erzeugten weniger akustische Strömungen (Ahmad et al. 1987) und sind daher nicht empfehlenswert. Weicher Draht hat den entscheidenden Vorteil, dass dieser keine scharfen Kanten besitzt und es daher nicht zu instrumentenbedingtem Substanzabtrag kommt. Bei der passiven Ultraschallspülung handelt es sich daher vielmehr um eine „nicht-schneidende Ultraschallspülung“, indem das Instrument in den flüssigkeitsgefüllten Wurzelkanal eingebracht wird und ohne Wandkontakt schwingt. Zuvor muss der Wurzelkanal jedoch ausreichend weit präpariert werden, sodass der Draht frei im Wurzelkanal schwingen kann.

Die Antriebe der Ultraschallgeräte übersetzen einen piezoelektrischen oder magnetostriktiven Effekt in elektrische Energie als Ultraschallwellen. Beide Methoden der Ultraschallerzeugung zeigten hierbei eine gleiche Wirkung (Cameron 1995). 
Die Schwingung der Spülspitze überträgt bestimmte hydrodynamische Muster auf die Flüssigkeit. Die Feilengeometrie stimmt dabei mit den hydrodynamisch erzeugten Mustern überein, sodass sich Schwingungsbäuche und -knoten bilden (van der Sluis et al. 2007a). Die hierbei erzeugten Strömungen werden auch als akustische Mikroströmung bezeichnet. Sobald jedoch die Instrumentenspitze nicht mehr frei im Wurzelkanal schwingen kann, kommt es zu einer teils deutlichen Reduktion dieser Mikroströmungen und dadurch zu einer Reduktion der Reinigungswirkung (Roy et al. 1994). Die resultierende akustische Strömung ist umgekehrt abhängig von der vom Instrument berührten Oberfläche.

Da die maximale Amplitude der Spülspitze sich an der Spitze befindet, ist daher auch der Abstand der Spülspitze zur Arbeitslänge von besonderem Interesse, um eine optimale Reinigung zu gewährleisten. In einer Studie mit extrahierten Zähnen und intrakanalär präparierten Vertiefungen in unmittelbarer Apexnähe wurde festgestellt, dass die Ultraschallspülung ebenfalls eine Auswirkung auf Seitenkanäle ausübt, insbesondere im apikalen Drittel des Wurzelkanals. Eine optimale Reinigungswirkung wird bei einer Insertionstiefe der Spülspitze von Arbeitslänge minus $3 \mathrm{~mm}$ erzielt (Jiang et al. 2011; Malki et al. 2012). Die Untersuchungen von Malki et al. wurden mit Farbpartikeln in Plastikblöcken ausgeführt, um die Arbeitshypothese zu bestätigen, dass ein Zusammenhang zwischen den Spülwirbeln und der Reinigung besteht.
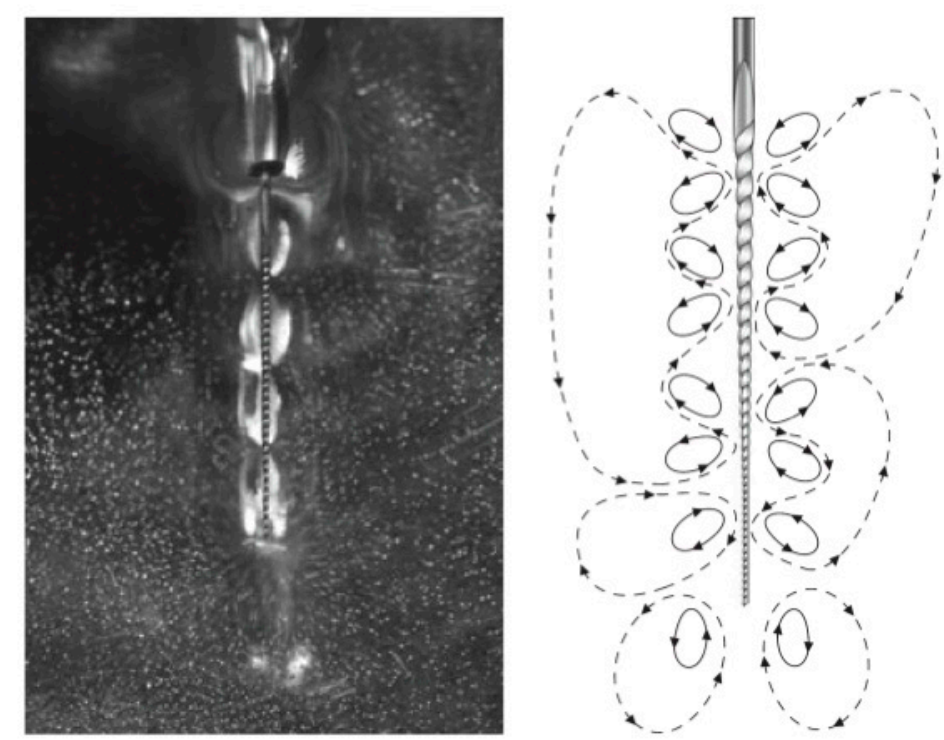

Abbildung 3: Akustische Mikroströmungen entlang einer Feile in Wasser und als Schema (aus van der Sluis et al. 2007 S. 418). 
Die Schwingungsenergie der passiven Ultraschallspülung wird auf die Partikel der Spülflüssigkeit übertragen, die sich in Form von Wärme äußern müsste. Ahmad (1990) stellte jedoch fest, dass sich der Temperaturanstieg um $0,6^{\circ} \mathrm{C}$ bei einer Ausgangstemperatur von $20^{\circ} \mathrm{C}$ in Grenzen hält und kaum einen nennenswerten Effekt auf die Reinigungswirkung und Bakterien haben kann.

Ebenfalls keinen signifikanten Unterschied konnte die Gruppe um Sabins et al. (Sabins et al. 2003) bei der Dauer der Ultraschallspülung feststellen. Jedoch wurde hier nur die Reinigungswirkung bei $30 \mathrm{~s}$ und $60 \mathrm{~s}$ Ultraschallspülung untersucht.

Die Konizität des Wurzelkanallumens scheint wie bei der Handspülung einen positiven Effekt auf die Reinigungswirkung zu besitzen. In den Untersuchungen von Lee et al. (2004b) und van der Sluis (2005a) ergab sich, dass sich Dentindebris aus Kanalerweiterungen bei größerer Konizität besser entfernen ließ (Lee et al. 2004a; van der Sluis et al. 2005b). Die Ergebnisse zeigten allerdings keine statistisch eindeutige Signifikanz, sodass lediglich von einer geringen Verbesserung gesprochen werden kann.

Vergleichsweise bedeutsam ist jedoch die Wirkung der PUI (passive ultrasonic irrigation) auf den Biofilm und somit die assoziierten antibakteriellen Eigenschaften des Systems. Sowohl Cunningham (1982) als auch neuere Studien (Halford et al. 2012; Cachovan et al. 2013) zeigten, dass die Ultraschallspülung einen besonders positiven Effekt auf die Zerstörung des Biofilmes hat. In beiden Studien zeigte sich bei mit $E$. faecalis infizierten extrahierten Zähnen eine deutlich bessere Desinfektionswirkung der PUI als der Handspülung. Der Zusatz von 0,2\%igem Chlorhexidin führte zu einer noch besseren Desinfektion. Halford et al. (2012) untersuchten dabei auch die Wirkung einer Mikrobläschenemulsion auf den Biofilm und entdeckten, dass die Energie, die bei dem Kollaps der Mikrobläschen verursacht wird, eine kraftvolle Schockwelle erzeugt, die energetisch ausreichend ist, um den Biofilm noch besser zu zerstören. Die antibakterielle Wirkung der PUI mit 1\%iger $\mathrm{NaOCl}-$ Lösung bei einminütiger Aktivierung könnte sogar so ausgeprägt sein, dass sie gleichgute Ergebnisse in der Reduktion der Keimzahl erzielt wie eine 7-tägige medikamentöse Einlage mit Kalziumhydroxid (Harrison et al. 2010). 
Da die Methode, zuerst Spülflüssigkeit in den Wurzelkanal zu applizieren und dann eine finale Aktivierung dieser Lösung durchzuführen, anerkannt und verbreitet ist, können auch weiterentwickelte Konzepte der Aktivierung noch eine Verbesserung der Desinfektion des endodontischen Systems erzielen (Jiang et al. 2012). Eines dieser Konzepte stellt die Continuous Ultrasonic Irrigation (CUI) dar, einer weiterentwickelten Form der PUI. Bei diesem System wird ständig die Spülflüssigkeit durch die Spülspitze erneuert, sodass permanent frische Spüllösung und damit unverbrauchte Chlorit-lonen zur Verfügung stehen. Die Verbesserung äußert sich dabei in der Reinigung der Seitenkanäle im apikalen Drittel des Zahns. Hierbei wurden mit der PUI lediglich $30 \%$ und bei der CUI jedoch 67,5\% der Seitenkanäle penetriert (Castelo-Baz et al. 2012). Eine weitere Studie ergab, dass die Reinigungswirkung der CUI im Vergleich zu anderen Abschlussspülungen wie der Handspülung, EndoVac und vertikal bewegten Guttapercha-Points (mit und ohne Taper) die beste Entfernung von smear layer, Dentindebris und Toxinen darstellt (Jiang et al. 2012).

Mehre In-vitro-Studien befassten sich mit der Entfernung von Debris aus Gruben und präparierten Vertiefungen in Wurzelkanälen extrahierter Zähne. Die PUI war der konventionellen manuellen Spülung mit einer Spülkanüle in der Reinigungswirkung deutlich überlegen (Sabins et al. 2003; Lee et al. 2004a; Rödig et al. 2010a). Jedoch darf auch nicht unerwähnt bleiben, dass in einer Invivo-Studie bei einer Fallzahl von 84 Zähnen mit einer apikalen Aufhellung im Röntgenbild, die durch eine Wurzelkanalbehandlung therapiert wurde, es keinen Unterschied machte, ob zusätzlich zu der manuellen Handspülung noch eine Abschlussspülung mit Ultraschall erfolgte. Es erfolgte jedoch auch keine medikamentöse Einlage, sodass man von einer PUI bei einer single-visitBehandlung keinen allzu großen Effekt zu erwarten hat (Liang et al. 2013).

\subsubsection{Schallaktivierte Spülung}

Verschiedene Spültechniken sind technisch im Bereich der schallaktivierten Spülspitzen angesiedelt. Gekennzeichnet sind diese durch Frequenzen im Bereich zwischen 1000 und $6000 \mathrm{~Hz}$. In Spülflüssigkeiten zeigten schallbetriebene Spülspitzen einen Schwingungsbauch an der Spitze und einen 
Schwingungsknoten an der Basis der Spülspitze (van der Sluis et al. 2007a). Wenn nun die Feile während einer Spülung nicht bewegt wird, bildet sich eine stehende Welle, die leichte Abrasionen über die gesamte Länge an der Wurzelkanalwand verursacht. Bei bewegten Schallspitzen tritt jedoch eine Spanbildung in der Wurzelkanalwand auf (Lumley et al. 1996). Aus der niedrigen Frequenz resultiert eine kleinere Scherspannung, die das Risiko einer Extrusion von Spülflüssigkeit über das Foramen apicale reduziert (Ahmad et al. 1987; Goode et al. 2013).

Es gibt verschiedene schallgesteuerte Spülspitzen auf dem Markt. Besonders viele Studien untersuchten den EndoActivator (Dentsply, Tulsa, USA) im Vergleich zur passiven Ultraschallspülung und klassischen Handspülung mit einer Spritze.

Bezogen auf die Sauberkeit steht die Studie von Jensen et al. (1999) ,die als einzige keinen Unterschied in der Sauberkeit von Wurzelkanalwänden feststellte, einer Vielzahl von Studien gegenüber, die der Ultraschallspülung eine bessere Sauberkeit zusprechen (Sabins et al. 2003; De Gregorio et al. 2010; Paragliola et al. 2010; Merino et al. 2013). Bezogen auf den klinischen Aspekt der Ausheilung einer apikalen Parodontitis sahen Huffaker et al. (2010) keinen Unterschied in der Keimzahlreduktion und somit kein System dem anderen als überlegen. Beide Methoden zeigten insbesondere im apikalen Drittel Defizite (Huffaker et al. 2010).

Eine genaue Beurteilung scheint daher systemabhängig zu sein, da bei den schallbetriebenen Spülspitzen die Feilengeometrie und Oberflächenbeschaffenheit ausschlaggebend sind (Lumley et al. 1996). 


\section{$3 \quad$ Ziele der Studie}

Das Ziel der vorliegenden Studie ist es, die Effektivität der Reinigung des Wurzelkanals mit Hilfe ultraschall- und schallbasierter Spültechniken mit und ohne zusätzlicher Anwendung kolloidaler Nanopartikel zu vergleichen.

Folgende Spültechniken werden untersucht:

- Die passive Ultraschallspülung

- Die schallbasierte Spülung

- Die manuelle Handspülung

Die Spültechniken werden jeweils mit Natriumhypochloritlösung und mit einer Spülflüssigkeit getestet, die Nanopartikel auf Hydroxylapatitbasis beinhaltet. 


\section{Material und Methoden}

Das Studienprotokoll wurde von der Ethik-Kommission der UMG unter der Nummer DOK_28_2016 genehmigt.

In der vorliegenden Studie wurden 74 extrahierte Zähne randomisiert in vier experimentelle Gruppen zu je 15 Zähnen und zwei Kontrollgruppen mit je 7 Zähnen für die konventionelle Handspülung eingeteilt.

\subsection{Auswahl der Zähne}

Die Zähne wurden alle im Zeitraum eines Jahres gesammelt und zunächst in Wasser gelagert.

Dabei galten die folgenden Einschlusskriterien:

- Inzisivi oder einwurzelige Prämolaren

- Unbeschädigter Apex

- Keine bisherigen endodontischen Maßnahmen

- Keine Zahnfrakturen oder Wurzelkaries

- Keine überkronten Zähne

- Vorlage einer Einwilligung der Patienten zur Verwendung ihrer nicht aus Studiengründen extrahierten Zähne zu wissenschaftlichen Zwecken

Ausschlusskriterien waren:

- Mehrwurzelige Zähne

- Nicht abgeschlossenes Wurzelwachstum

- Deformationen oder ungerader Wurzelverlauf

- Frühere endodontische Maßnahmen

- Zahnfrakturen oder Wurzelkaries

- Überkronte Zähne

- Fehlende Patienteneinwilligung 


\subsection{Voruntersuchungen}

Um eine Standardisierung zu gewährleisten, wurden Voruntersuchungen an fünf Zähnen mit den gleichen Einschlusskriterien durchgeführt. Dies diente vor allem dazu, sowohl die Präparationstechnik als auch die Herstellung der Gruben und Löcher zu erproben und zu vereinheitlichen. Da bis zur Versuchsdurchführung noch keine Studien zur Verwendung von Nanopartikeln als Spülflüssigkeit im Wurzelkanal vorlagen, musste ebenfalls erprobt werden, ob überhaupt eine Aktivierung dieser Flüssigkeiten mit Schall- und Ultraschallinstrumenten möglich ist.

Bei den Voruntersuchungen stellte sich insbesondere das Problem heraus, dass die Nanopartikel in einer hochviskösen Suspension vorliegen. Es wurde entschieden, die unverdünnte Flüssigkeit als Spülmedium zu verwenden.

Die Nanopartikel werden nach abgeschlossener Spülung nur schlecht von Papierspitzen aufgenommen. Lediglich die Oberfläche der Papierspitzen dient den Nanopartikeln als Anhaftungsfläche, um diese zu entfernen. Da sowohl der Dentindebris als auch die Nanopartikel weiß sind, musste eine Möglichkeit gefunden werden, verbliebenes Dentin in den präparierten Gruben und Löchern von Nanopartikeln zu unterscheiden. Daher wurde nach jedem Spülzyklus die verbliebene Spülflüssigkeit mit einer 22 Gauge Kanüle, die mit Silaplast auf einen großen Sauger montiert wurde, aus dem koronalen Bereich der Zugangskavität abgesaugt. Dies diente vor allem auch der Erneuerung der Spülflüssigkeit der Nanopartikel, da weder die PUI noch die schallaktivierte Spülung es schafften, die Flüssigkeit aus dem Wurzelkanallumen zu entfernen und durch frische Lösung zu ersetzen. Um ein Einpressen der Nanopartikel in die Gruben zu vermeiden, wurde zunächst mit dünnen Papierspitzen der Großteil der Lösung passiv abgesaugt und dann zunehmend dickere Spitzen verwendet.

\subsection{Präparation der Zähne}

Die in die Studie eingeschlossenen Zähne wurden gesäubert und desinfiziert. Die harten und weichen Beläge wurden von der Wurzeloberfläche mit Scalern (HLW-Germany, Wernberg-Köblitz) entfernt. Anschließend wurden die Zu- 
gangskavitäten mit hochtourig rotierenden Diamantschleifern (Brasseler, Lemgo) präpariert. Sobald das Dach der Pulpakammer erreicht wurde, wurden alle Dentinüberhänge mit einem Rosenbohrer entfernt und die Kavitätenwände mit einem diamantierten Ultraschallansatz (KaVo, Biberach/Riß) geglättet.

Die Zähne wurden mit einem Reamer der ISO-Größe 10 (VDW GmbH, München) sondiert und leicht überinstrumentiert, um die Durchgängigkeit des apikalen Foramens zu überprüfen. Dabei wurde der Reamer vorsichtig über das Foramen apicale geschoben und wieder zurückgezogen, sobald die Spitze des Reamers gerade sichtbar war.

Die Länge der Zähne betrug 20-29 mm und wurde mit Diamantschleifern auf 19 mm gekürzt, um eine einheitliche Länge des Probenmaterials zu schaffen.

Mit Gates-Glidden-Bohrern (Brasseler, Lemgo) der Größen III und II wurden die Wurzelkanaleingänge koronal erweitert, um einen Gleitpfad für die weitere maschinelle Bearbeitung herzustellen. Dabei wurde die Arbeitslänge der GatesGlidden-Bohrer III auf $4 \mathrm{~mm}$ und die des Gates-Glidden-Bohrers II auf $6 \mathrm{~mm}$ ab dem koronalen Referenzpunkt festgelegt.

Anschließend erfolgte die maschinelle Wurzelkanalpräparation mit Hilfe des Mtwo-Systems (VDW GmbH, München) bis zur Größe 40/.04 in der CrownDown-Technik. Die Abfolge der Nickel-Titan-Feilen erfolgte nach Herstellerangaben. Die Arbeitslänge wurde auf $18 \mathrm{~mm}$ festgelegt. Nach achtmaligem Gebrauch wurden die Instrumente auf Empfehlung des Herstellers verworfen.

Zwischen den Instrumentierungen wurden die Wurzelkanäle mit $2 \mathrm{ml} 3 \%$ $\mathrm{NaOCl}-L o ̈ s u n g ~(H e d i n g e r$, Stuttgart) gespült. Die Spülung erfolgte manuell mit einer $5 \mathrm{ml}$ Spritze (B. Braun, Melsungen) und einer Kanüle der Größe 30 (Endoneedle, Vedefar, Dilbeek, Belgien), um sicherzustellen, dass das Spülvolumen zwischen den Präparationsinstrumenten konstant ist.

Präparation und Spülung wurden von demselben Behandler ausgeführt, um möglichst gleiche Verhältnisse sowohl bei der Präparation als auch bei der Spülung zu erzielen. Die Abschlussspülung wurde mit $5 \mathrm{ml}$ 17\%igem EDTA (Ethylendiamintetraessigsäure) (Lege artis pharma, Dettenhausen) und $5 \mathrm{ml}$ $3 \%$ igem $\mathrm{NaOCl}$ durchgeführt. 
Anschließend wurde der Wurzelkanal mit Papierspitzen (Henry Schein, Melville, USA) getrocknet.

Um eine spätere Repositionierung der Wurzelhälften zu gewährleisten, wurden Silikonformen in einem Rohr aus Acrylglas (alt-intech, Neresheim) und Silaplast (Dentax, Ettlingen) hergestellt. Dabei wurden die Zähne in die noch verformbare Silikonmasse gedrückt. Das Acrylglasrohr diente der Formgebung und Stabilisierung des Silikons (Abbildung 4).

\subsubsection{Präparation der Gruben und Löcher}

Anschließend wurden standardisierte Gruben und Löcher in die Wurzeln präpariert. Dieser Versuchsaufbau ist angelehnt an Lee et al. (2004a) und hat sich mehrfach in anderen Studien bereits bewährt (van der Sluis et al. (2005a,b); Rödig et al. (2010b); Jiang et al. (2010a); Srirekha et al. (2012)).

Ein Guttapercha-Stift der Größe ISO 40 wurde in den Wurzelkanal eingebracht, um von außen die Dimension des Wurzelkanals besser einschätzen zu können. Entlang der mesialen und distalen Längsachsen der Zähne wurde mit einer diamantierten Trennscheibe (Horico, Berlin) eine Rille angelegt, ohne hierbei das Kanallumen zu eröffnen und die Zähne longitudinal gespalten. Es wurde mit Hilfe eines Mikroskops (OPMI pico, Carl Zeiss, Jena) kontrolliert, ob die Zähne wieder lückenlos reponiert werden konnten. Falls dies nicht der Fall war, wurden die Zähne aus der Studie ausgeschlossen. Zähne, die bei dem Spaltungsprozess zerstört wurden, sodass das Wurzelkanallumen sich als lateral eröffnet darstellte, wurden ebenfalls aussortiert und durch neue Zähne ersetzt, da ein späterer Austritt der Spülflüssigkeiten die mikrodynamischen Strömungsmuster der Spülspitzen abgeändert hätte.

Die Anordnung der Grube und der Löcher wurde zuvor abgemessen und mit einem Bleistift auf der Seite des Zahnes markiert.

Zur Präparation der Gruben wurde ein Fingerspreader (VDW GmbH, München) der ISO Größe 35 verwendet. Nach Abtrennen des Handgriffs wurde die Spitze des Fingerspreaders „"“-förmig mit einer diamantierten Trennscheibe modifiziert (Abbildung 5), sodass eine einheitlich breite Grube präpariert werden konnte. Die Gruben beginnen dabei in einem Abstand von $2 \mathrm{~mm}$ koronal des Apex und wurden insgesamt auf eine Länge von $4 \mathrm{~mm}$ in die Kanalwand präpariert. 
Hierzu wurde der abgetrennte Fingerspreader in den Nadelhalter eines Ultraschallgerätes (VDW Ultra, VDW GmbH, München) inseriert und bei niedriger Frequenz präpariert. Es entstanden so $4 \mathrm{~mm}$ lange, $0,2 \mathrm{~mm}$ breite und $0,5 \mathrm{~mm}$ tiefe Kavitäten (siehe Abbildung 6 und 8). Die Kavitäten stellen bei diesem Versuch durch normale Spülungen nicht direkt erreichbare und nicht effizient spülbare Bereiche dar.

Die andere Zahnhälfte wurde genutzt, um runde Löcher zu präparieren, die nicht instrumentierte Seitenkanäle simulieren sollten. Die runden Kavitäten wurden mit einem Rosenbohrer mit dem Durchmesser 0,3 mm (H71.104.003, Komet, Lemgo) im Abstand von 2, 4 und $6 \mathrm{~mm}$ koronal der Arbeitslänge angelegt (siehe Abbildung 7 und 9). Die Dimensionen und die Positionierung der runden Kavitäten wurden von Lee et al. (2004) übernommen (siehe Abbildung 10).

Somit sind in jedem Wurzelkanal zwei anatomisch schwierig zu reinigende Areale vorhanden: Ovale Wurzelkanalbereiche, die nicht direkt bei der maschinellen Präparation instrumentiert wurden, und Seitenkanäle im apikalen Drittel des Zahnes. 


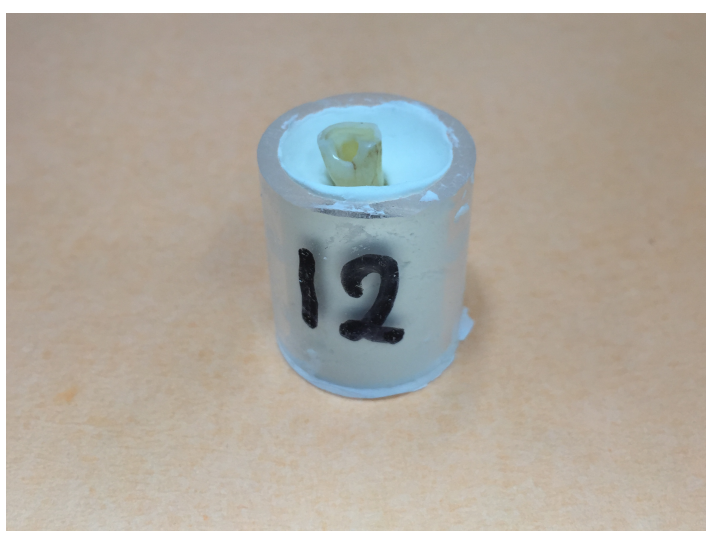

Abbildung 4: Montierter Zahn in der Silikonmasse

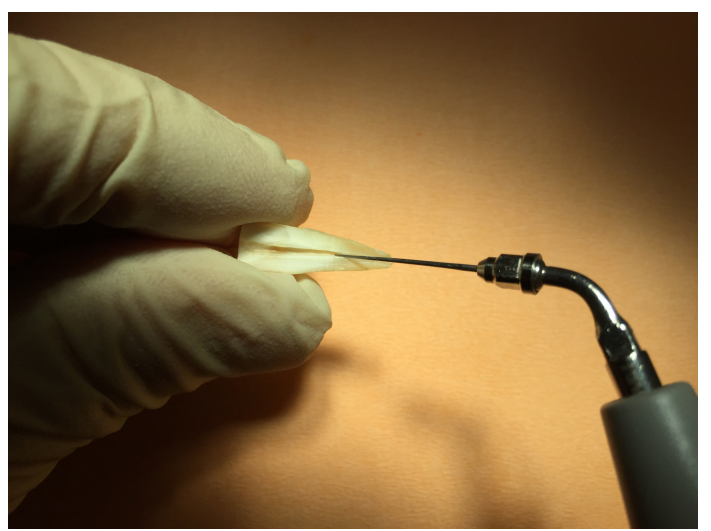

Abbildung 6: Präparation der Grube

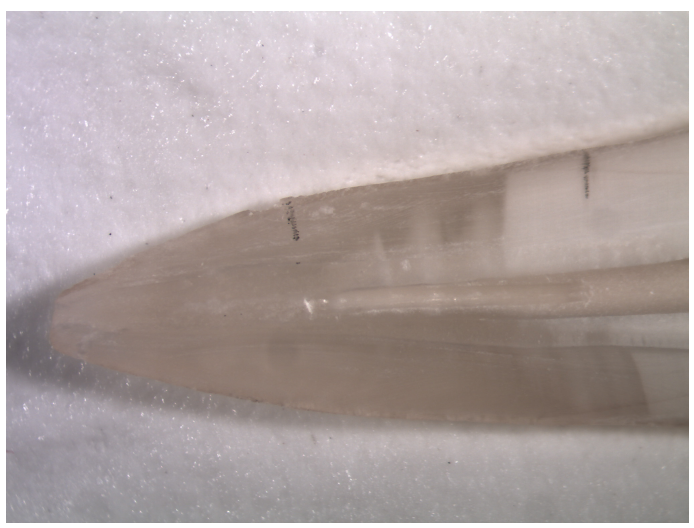

Abbildung 8: Präparierte Grube

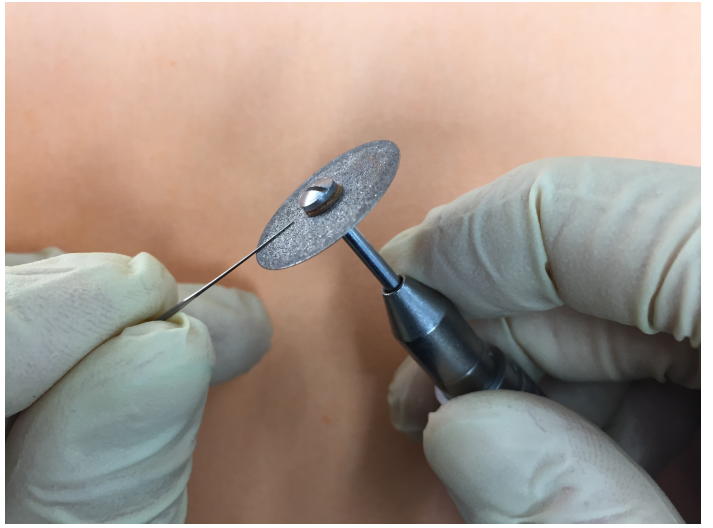

Abbildung 5: Modifizierung des

Fingerspreaders mit einer Trennscheibe

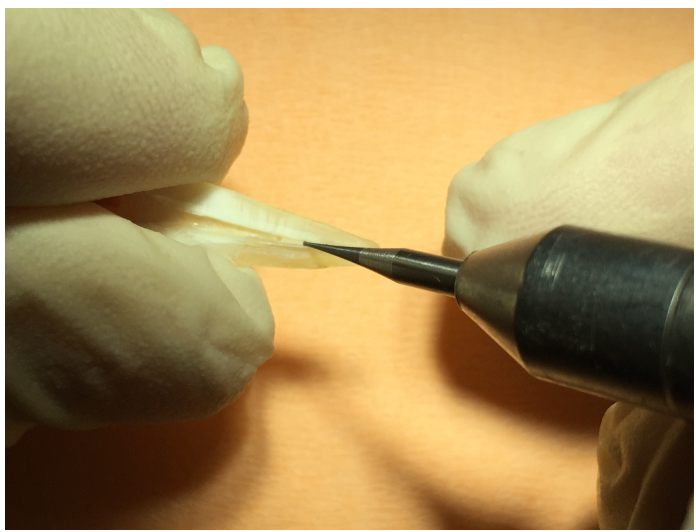

Abbildung 7: Präparation der Löcher

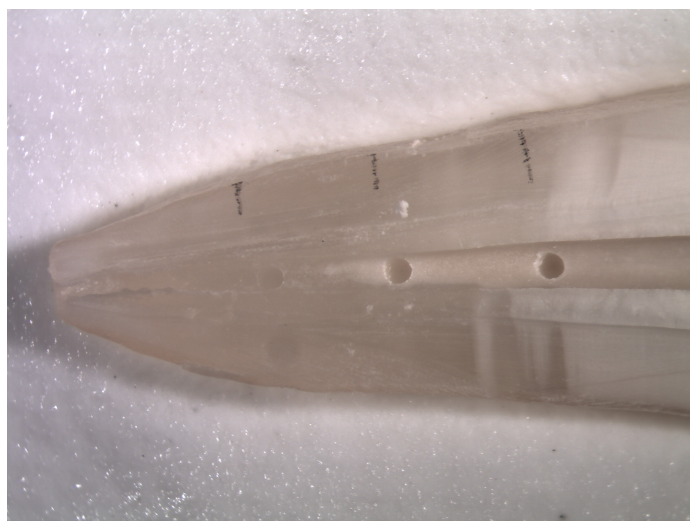

Abbildung 9: Präparierte Löcher 


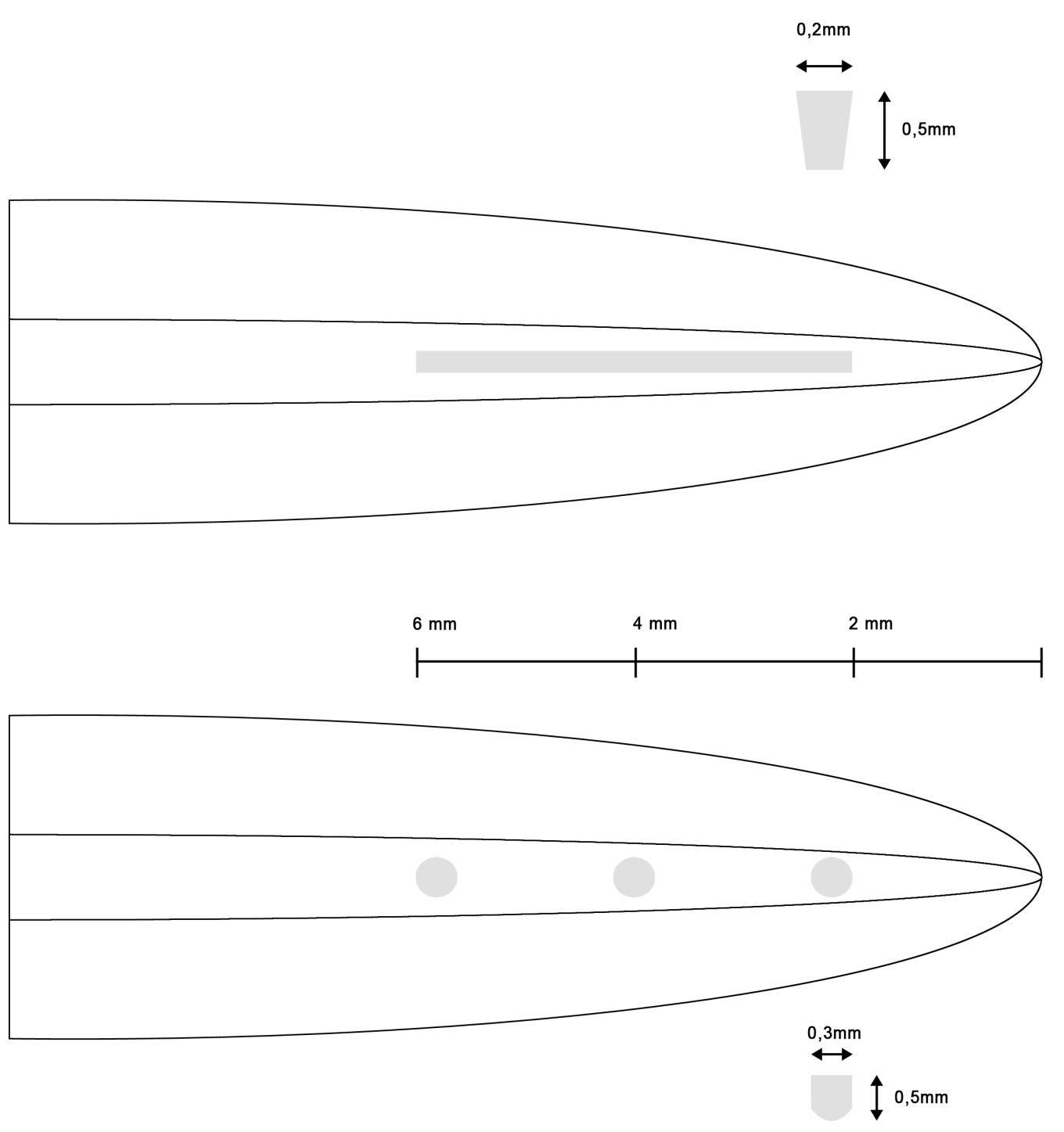

Abbildung 10: Position der Gruben und Löcher in den Zahnwurzelhälften

\subsubsection{Fotografische Dokumentation der Versuchsreihen}

Zur eindeutigen Beurteilung der präparierten Gruben und Löcher dienten Fotografien, die unter einem Mikroskop (Stemi SV 11, Zeiss, Jena) angefertigt wurden. Um mögliche Fehlerquellen auszuschließen, wurden zuvor Silikonschlüssel aus Silaplast (Dentax, Ettlingen) angefertigt, die es ermöglichten, die Zahnhälften im Verlauf der Studie eindeutig zu repositionieren. Diese exakte Repositionierung diente auch dazu, die Gruben gut auszuleuchten und Schattenwürfe oder Veränderungen zu vermeiden, die die spätere Beurteilung beeinflussen könnten. Mit einer Kamera (moticam 2300, Wetzlar) wurde bei vierfacher Vergrößerung ein Foto von jeder Wurzelhälfte und von 
allen Gruben und Löchern bei optimaler Ausleuchtung angefertigt. So entstanden im Verlauf der Versuche von jedem Zahn sieben Fotos:

- Ein Übersichtsfoto, das beide Zahnhälften zeigt

- Leere Gruben und Löcher

- Mit Dentindebris gefüllte Gruben und Löcher

- Gruben und Löcher nach der Reinigung mit den unterschiedlichen Verfahren

\subsection{Dentinspäne}

Die Dentinspäne wurde aus der Innenseite von präparierten Wurzelkanälen gewonnen, die während der Probenherstellung aus den Versuchen ausgeschlossen wurden. Mit einem Rosenbohrer (Komet, Lemgo) wurde bei niedriger Umdrehung langsam an den Wurzelkanalwänden dieser Zähne Dentin abgetragen. Um möglichst frische Dentinspäne zu gewinnen, wurde eine entsprechende Menge direkt vor der Befüllung der Gruben und Löcher gewonnen. Die Späne wurde vor dem Befüllen mit einigen Tropfen $\mathrm{NaOCl}$ angemischt, um die typische treibsandartige Konsistenz des Dentindebris zu erhalten.

\subsection{Befüllen der Gruben und Löcher}

Das Befüllen der Gruben und Löcher mit dem Dentindebris fand unter einem Mikroskop bei 10-facher Vergrößerung statt. Zuvor wurden unter dem Mikroskop die Beschaffenheit der Gruben und Löcher begutachtet und Bearbeitungsreste mit einer weichen Zahnbürste (GABA, Lörrach) beseitigt. In die künstlich geschaffenen Vertiefungen wurde nun der Dentindebris unter leichtem Druck mit Guttaperchastiften (VDW GmbH, München) der Größen 15 und 40 eingebracht. Der leichte Druck war notwendig, um sicherzustellen, dass die Gruben und Löcher auch gänzlich gefüllt und nicht nur oberflächliche Bereiche mit Dentindebris bedeckt waren.

Reste von Dentindebris, der sich nicht in den Gruben und Löchern befand, wurden mit Papierspitzen (Multident Dental, Oldenburg), die leicht mit Natriumhypochlorit befeuchtet wurden, tupfend entfernt.

Als Abschlusskontrollen dienten das Kippen der Zahnhälften unter dem 
Mikroskop, um nicht gefüllte Randbereiche zu erkennen und die Inspektion des Fotos der gefüllten künstlichen Vertiefungen.

\subsection{Spülung der präparierten Wurzelkanäle}

Die weitere Spülung der Wurzelkanäle erfolgte mit unterschiedlichen Systemen und Spülflüssigkeiten. Die Spülflüssigkeiten wurden manuell mit einer Spritze (B. Braun, Melsungen) und Kanülen der Größe 30 (Endoneedle, Vedefar, Dilbeek, Belgien) in den Wurzelkanal appliziert. Dabei wurde darauf geachtet, dass die Spülkanüle maximal auf Arbeitslänge minus $2 \mathrm{~mm}$ und ohne Wandkontakt inseriert wurde. Die Spülflüssigkeiten Natriumhypochlorit 3\% (Hedinger, Stuttgart) und VECTOR Fluid polish (DÜRR Dental, BietigheimBissingen) wurden in die vorbereiteten Wurzelkanäle appliziert. Die Aktivierung der Spüllösungen erfolgte mit der schallaktivierten Nickel-Titan-Spitze SF 65 (Komet, Lemgo) oder der ultraschallaktivierten Metallspitze IrriSafe 20-21 (Acteon, Mettmann) nach einem standardisierten Spülprotokoll.

\subsubsection{Passive Ultraschallspülung (PUI)}

Die Ultraschallspülung erfolgte mit einer IrriSafe-Spitze der ISO-Größe 20 (Acteon, Mettmann), die in den Ultraschallgenerator VDW Ultra (VDW GmbH, München) eingeschraubt wurde. Der Ultraschallgenerator gibt mehrere Verwendungsbereiche entsprechend der generierten Frequenz an. Die ersten $30 \%$ dienen der Aktivierung von Spülflüssigkeiten, es folgt der Bereich mit $40 \%$ bis $60 \%$ der Maximalfrequenz zur Präparation mit diamantierten Aufsätzen. Ab $60 \%$ Geräteleistung bis zur Maximalintensität des Ultraschallgenerators wird die Anwendung bei Revisionsbehandlungen und zur Entfernungen von Metallstiften empfohlen. Die Geräteeinstellung für die Versuche wurde auf 30\% festgelegt.

Die Spülspitze IrriSafe ist ein nichtschneidendes Instrument mit parallelen Rillen. Die Spitze ist abgerundet und wird vom Hersteller zur Beseitigung von Dentindebris insbesondere im apikalen Drittel der Wurzelkanäle beworben (Acteon 2011). 
Der Hersteller empfiehlt, die Spülspitze $2 \mathrm{~mm}$ vor Arbeitslänge einzubringen und während der Aktivierung in Hubbewegungen mit ca. $2 \mathrm{~mm}$ Amplitude aufund abzubewegen.

\subsubsection{Komet SF65}

Die SF 65 (Komet, Lemgo) ist eine Spitze zur abschließenden Spülung von Wurzelkanälen. Die Spitze wird in den Halter SF1981 in einem Schallhandstück montiert. Die Verriegelung erfolgt mit Hilfe einer Schraubverbindung, sodass nur die Spülspitze ausgetauscht werden muss. Laut Herstellerangaben kann die Spülspitze für 5 bis 8 Spülvorgänge verwendet werden und ist im Autoklav sterilisierbar. Die Spülspitze besteht aus Nickel-Titan und ist durch eine TitanNitrid-/TiN-Beschichtung gegen Korrosion durch Spülflüssigkeiten und Sterilisation geschützt. Die Beschichtung dient ebenfalls dazu, Unebenheiten auf der Instrumentenoberfläche auszugleichen (Schäfer 2002).

Die Spülspitze ist $25 \mathrm{~mm}$ lang und mit Längenmarkierungen im Bereich von 20 bis $22 \mathrm{~mm}$ und 16 bis $18 \mathrm{~mm}$ versehen. Die SF 65 hat einen Taper von $2 \%$ und besitzt eine abgerundete Spitze mit einem Durchmesser von $0,2 \mathrm{~mm}$.

Der Hersteller empfiehlt, die Spülspitze in den Wurzelkanal auf $2 \mathrm{~mm}$ koronal der Arbeitslänge einzubringen und dann auf einer geringen Leistungsstufe (vergleichbar mit der Stufe 1 bei dem Schallhandstück SF1LM (Komet, Lemgo)) zu aktivieren. In der vorliegenden Studie wurde das Schallhandstück SonicFlex 2003N (KaVo, Biberach/Riß) verwendet.

Zur Aktivierung werden leichte auf- und abwärts gerichtete Hubbewegungen durchgeführt. Es wird eine Aktivierung der Spülflüssigkeit für 15 Sekunden empfohlen, danach sollte das Spülmedium ausgetauscht werden.

Die SF 65 sollte ständig in Bewegung bleiben und nie an demselben Bereich im Wurzelkanal verbleiben, um eine Stufenbildung zu vermeiden (Komet Dental 2014). 


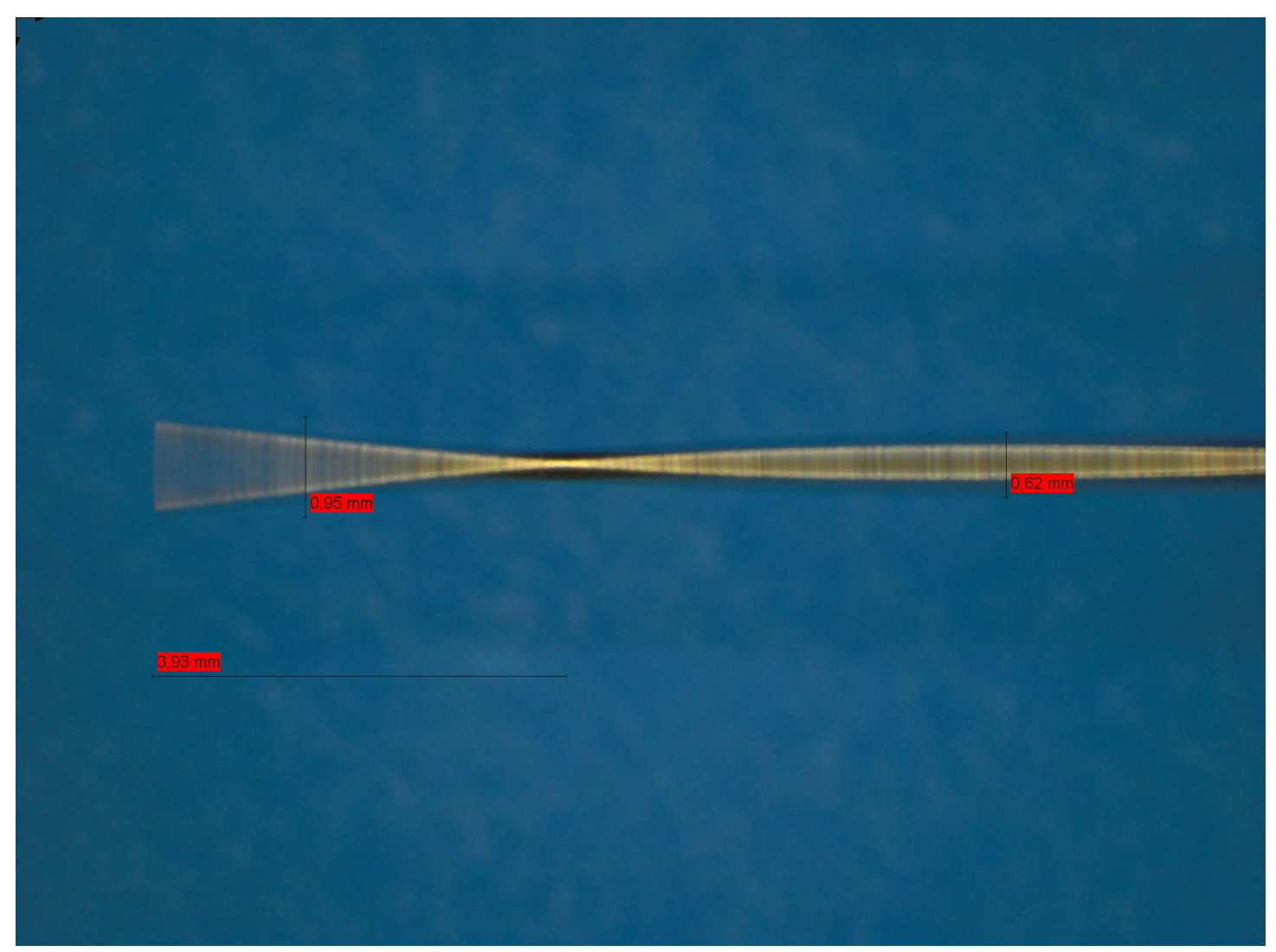

Abbildung 11: Komet SF65 in Luft schwingend. Mit freundlicher Genehmigung der Fa. Brasseler.

\subsubsection{Handspülung}

Die Handspülung wurde mit 5-ml-Spritzen (Braun, Melsungen) und 30 Gauge Kanülen (Endoneedle, Vedefar, Belgien) durchgeführt. Die Längenkontrolle erfolgte mit einem Gummistopper auf $16 \mathrm{~mm}$ Länge. Das Spülvolumen wurde auf $10 \mathrm{ml}$ für 60 Sekunden Gesamtspülzeit in drei Intervallen á 20 Sekunden festgelegt. Während der Spülung wurde die Kanüle ebenfalls in $2 \mathrm{~mm}$ hohen Hubbewegungen auf- und ab bewegt.

\subsection{Versuchsablauf}

Nachdem die präparierten Gruben mit Dentindebris gefüllt worden waren, wurden die Zähne vorsichtig wieder lückenlos zusammengefügt. Peripheriwachs (Sigma Dental, Handewitt) wurde zur Stabilisierung in die Schleifrille gefüllt, sodass garantiert werden konnte, dass keine Spülflüssigkeit seitlich austritt. Anschließend wurden die Zähne in die zuvor angefertigten Silikonformen reponiert. 


\subsubsection{Versuchsgruppen}

\subsubsection{Gruppe 1: Komet SF 65 mit NaOCI}

15 Zähne

Spülprotokoll:

- Auffüllen des Wurzelkanals mit NaOCl

- Einbringung der SF 65 auf 16 mm ab Wurzelkanaleingang (Beginn der ersten Farbmarkierung)

- 3 Spülzyklen á 20 Sekunden

- Absaugen des verbliebenen Spülmediums bis in den präparierten Wurzelkanal hinein mit einer 22 Gauge Kanüle - nach jedem Spülzyklus wurde das Spülmedium wieder aufgefüllt

- Hubbewegungen von 2 mm während der Spülung mit der SF65

\subsubsection{Gruppe 2: Komet SF 65 mit Nanopartikeln}

15 Zähne

Spülprotokoll:

- Auffüllen des Wurzelkanals mit Vector polish

- Einbringung der SF 65 auf 16 mm ab Wurzelkanaleingang (Beginn der ersten Farbmarkierung)

- 3 Spülzyklen á 20 Sekunden

- Absaugen des verbliebenen Spülmediums bis in den präparierten Wurzelkanal hinein mit einer 22 Gauge Kanüle - nach jedem Spülzyklus wurde das Spülmedium wieder aufgefüllt

- Hubbewegungen von 2 mm während der Spülung mit der SF65

\subsubsection{Gruppe 3: PUI mit NaOCI}

15 Zähne

Spülprotokoll:

- Auffüllen des Wurzelkanals mit $\mathrm{NaOCl}$

- Einbringung der IrriSafe Spülspitze ISO 20 auf $16 \mathrm{~mm}$ ab Wurzelkanaleingang (Beginn der ersten Drahtwindungen) 
- 3 Spülzyklen á 20 Sekunden

- Absaugen des verbliebenen Spülmediums bis in den präparierten Wurzelkanal hinein mit einer 22 Gauge Kanüle - nach jedem Spülzyklus wurde das Spülmedium wieder aufgefüllt

- Hubbewegungen von 2 mm während der Spülung mit der Acteon Spülspitze ISO 20

\subsubsection{Gruppe 4: PUI mit Nanopartikeln}

15 Zähne

Spülprotokoll:

- Auffüllen des Wurzelkanals mit Vector polish

- Einbringung der Irrisafe Spülspitze ISO 20 auf $16 \mathrm{~mm}$ ab Wurzelkanaleingang (Beginn der ersten Drahtwindungen)

- 3 Spülzyklen á 20 Sekunden

- Absaugen des verbliebenen Spülmediums bis in den präparierten Wurzelkanal hinein mit einer 22 Gauge Kanüle - nach jedem Spülzyklus wurde das Spülmedium wieder aufgefüllt

- Hubbewegungen von $2 \mathrm{~mm}$ während der Spülung mit der Acteon Spülspitze ISO 20-21

\subsubsection{Gruppe 5: Handspülung mit NaOCl (Kontrollgruppe 1)}

\section{Zähne}

Spülprotokoll:

- Auffüllen des Wurzelkanals mit $\mathrm{NaOCI}$

- Einbringung der Kanüle auf 16 mm ab Wurzelkanaleingang

- 3 Spülzyklen á 20 Sekunden - Spülvolumen gesamt: 10 ml

- Absaugen des verbliebenen Spülmediums bis in den präparierten Wurzelkanal hinein mit einer 22 Gauge Kanüle - nach jedem Spülzyklus wurde das Spülmedium wieder aufgefüllt

- Hubbewegungen von 2 mm während der Spülung mit der Kanüle 


\subsubsection{Gruppe 6: Handspülung mit Nanopartikeln (Kontrollgruppe 2)}

\section{Zähne}

Spülprotokoll:

- Auffüllen des Wurzelkanals mit Vector polish

- Einbringung der Kanüle auf $16 \mathrm{~mm}$ ab Wurzelkanaleingang

- 3 Spülzyklen á 20 Sekunden - Spülvolumen gesamt: $10 \mathrm{ml}$

- Absaugen des verbliebenen Spülmediums bis in den präparierten Wurzelkanal hinein mit einer 22 Gauge Kanüle - nach jedem Spülzyklus wurde das Spülmedium wieder aufgefüllt

- Hubbewegungen von 2 mm während der Spülung mit der Kanüle.

\subsection{Auswertung}

Nach den Spülvorgängen wurden die Wurzelkanäle mit Papierspitzen der ISO Größen 25 bis 40 wieder getrocknet. Dabei wurde bei den mit Nanopartikeln gespülten Proben darauf geachtet, zunächst mit kleineren Papierspitzen dem Wurzelkanallumen die hoch viskösen Nanopartikel zu entziehen, um danach mit größeren Papierspitzen dieses zu trocknen, sodass ein Verdrängen der Flüssigkeit in die Gruben und Löcher vermieden werden konnte. Die Wurzelhälften wurden vorsichtig aus den Silikonformen entfernt und mit Hilfe der zuvor angefertigten Silikonschlüssel wieder unter einem Mikroskop für Fotos positioniert.

Die 148 Fotografien der gespülten Zähne wurden zu Paaren zusammen angeordnet, um die Fotos der Gruben und Löcher der korrespondierenden Wurzelhälften zueinander zuordnen zu können.

Die Menge des verbliebenen Debris wurde von zwei zuvor kalibrierten Untersuchern vorgenommen. Die Auswertung der Fotos fand an einem farbkalibrierten Monitor unter konstanten Lichtverhältnissen statt.

Bewertet wurde nach einem abgeänderten Scoresystem von Lee et al. (2004a), mit vier Abstufungen. Die Intervalle der Abstufungen waren gleich groß. Dabei galten folgende Bewertungsmaßstäbe: 
- Score 0: Die Grube oder Löcher ist zwischen 0\% - 25\% mit Debris gefüllt

- Score 1: Die Grube oder Löcher ist zwischen 26\% - 50\% mit Debris gefüllt

- Score 2: Die Grube oder Löcher ist zwischen $51 \%$ - 75\% mit Debris gefüllt

- Score 3: Die Grube oder Löcher ist zwischen 76\% - 100\% mit Debris gefüllt 


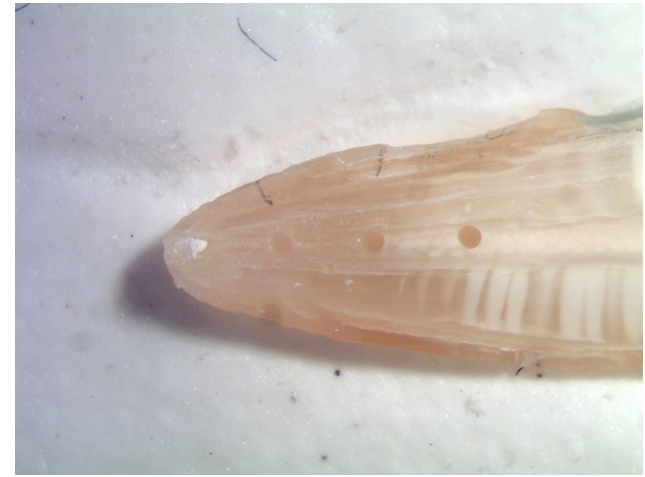

Abbildung 12: Löcher: Score 0

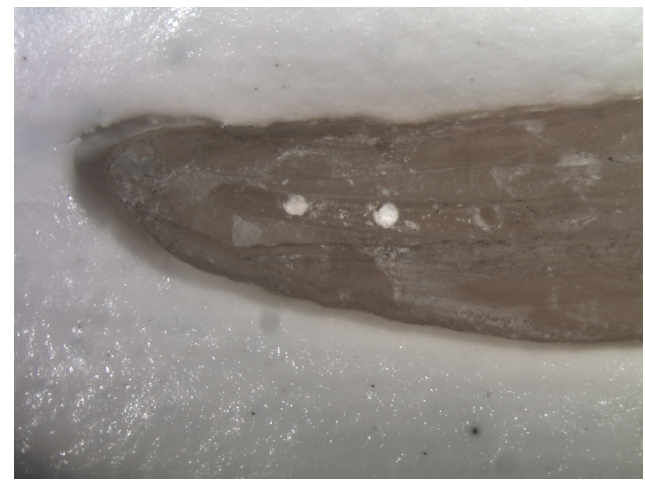

Abbildung 14: Löcher: Score 2

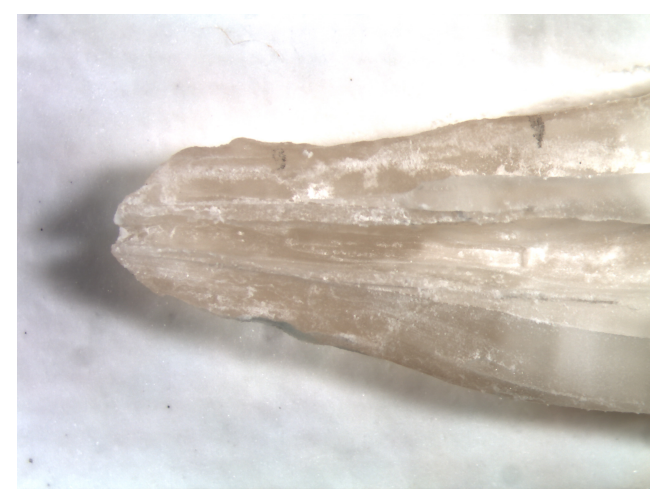

Abbildung 16: Grube: Score 0

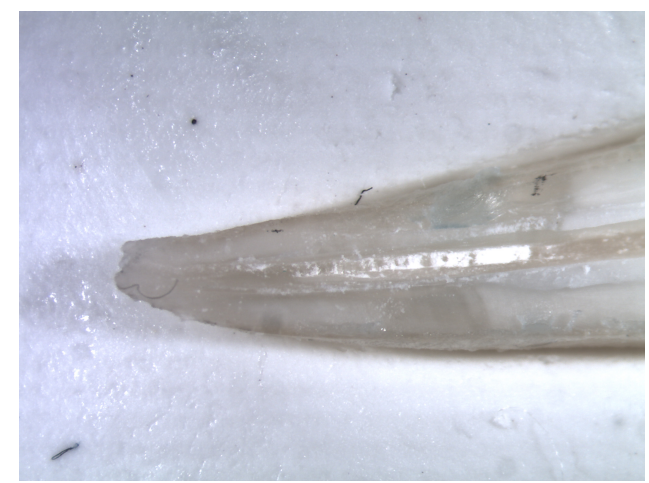

Abbildung 18: Grube: Score 2

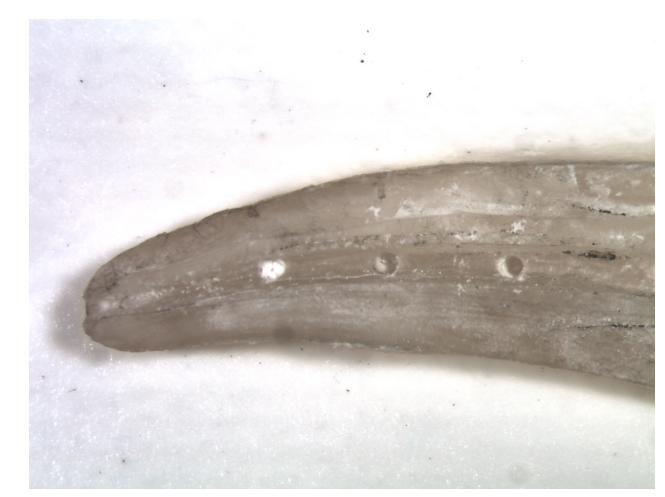

Abbildung 13: Löcher: Score 1

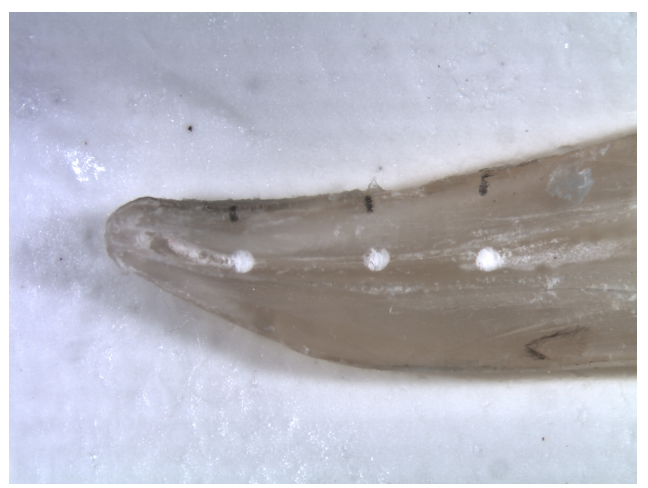

Abbildung 15: Löcher: Score 3

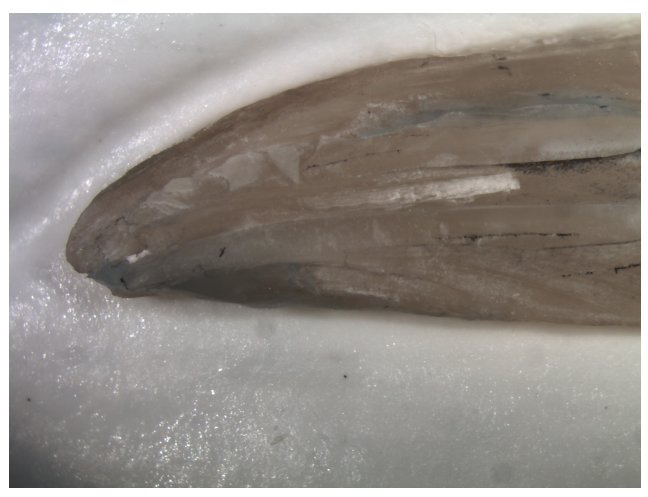

Abbildung 17: Grube: Score 1

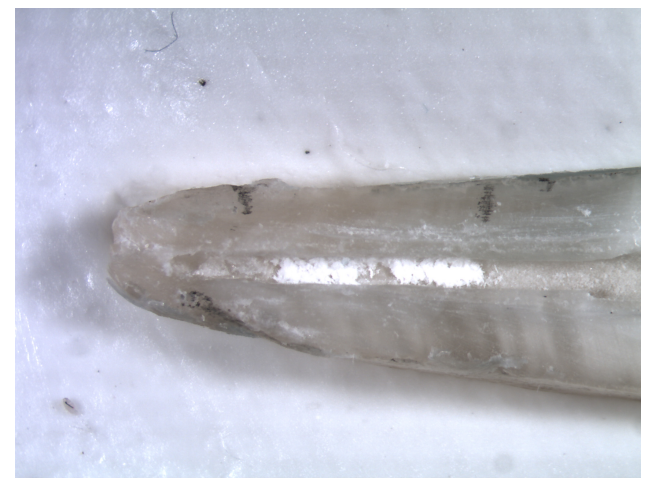

Abbildung 19: Grube: Score 3 


\subsubsection{Kalibrierung der Untersucher}

Die Kalibrierung der Untersucher fand anhand von Fotos aus den Versuchsreihen statt, die repräsentativ für die einzelnen Score-Werte standen. Es wurden 20 Fotos von Gruben und 20 Fotos von den Löchern ausgesucht, die dieses Spektrum abbildeten. Die insgesamt 40 Fotos wurden von beiden Untersuchern separat ausgewertet und bei fehlender Übereinstimmung besprochen. Nach einer Woche wurden dieselben 40 Fotos erneut ausgewertet. Die Bewertungen der zwei Untersucher mussten dabei eine Übereinstimmung des Kappa-Wertes von größer-gleich 0,8 aufweisen.

Im Anschluss wurden nach einer weiteren Woche alle 148 Fotos der gespülten Wurzelhälften nach dem oben genannten Score-System ausgewertet.

\subsection{Statistische Auswertung}

In die statistische Auswertung wurden die Bewertungen der beiden Untersucher 1 und 2 für die Gruben und Löcher einbezogen. Somit ergab sich eine Merkmalsausprägung von $n=296$ Werten. Die statistische Auswertung wurde mit dem Programm Statistica 12 vorgenommen. Die Tabellen und Diagramme wurden mit Statistica 12 und Excel Mac 2011 erstellt. 


\section{Ergebnisse}

\subsection{Ergebnisse der Kalibrierung}

\subsubsection{Interindividuelle Übereinstimmung und intraindividuelle Reproduzierbarkeit}

Nach einer Kalibrierung wurde untersucht, wie sich die Reproduzierbarkeit der Ergebnisse bei wiederholter Auswertung durch die beiden Bewerter darstellt (intraobserver reproducibility). Ebenfalls wurde kontrolliert, wie hoch die Übereinstimmung zwischen zwei Untersuchern ausfällt (interobserver agreement).

Untersucher 1 erzielte dabei zwischen der ersten und zweiten Kalibrierung einen Cohens Kappa-Wert von 0,958592. Untersucher 2 erzielte einen Cohens Kappa-Wert von 0,919759. Die intraindividuelle Reproduzierbarkeit ist in Abbildung 20 dargestellt. Ein Wert von größer-gleich 0,8 gilt als gute Reproduzierbarkeit einer Bewertung. Es kann also festgehalten werden, dass in der vorliegenden Studie die intraindividuelle Reproduzierbarkeit der Untersucher gewährleistet ist.

Die interindividuelle Übereinstimmung zwischen den beiden Untersuchern wurde durch den Fleiss Kappa-Koeffizienten bestimmt, da zwei Kalibrierungen vorgenommen wurden. Die beiden Untersucher erzielten hier eine Wertung von 0,857561. Auch bei dem Fleiss Kappa-Koeffizienten gilt eine gute Reproduzierbarkeit ab einem Wert größer-gleich 0,8. Zwischen den Untersuchern kann also von einer guten Übereinstimmung in der Bewertung der Proben gesprochen werden. 


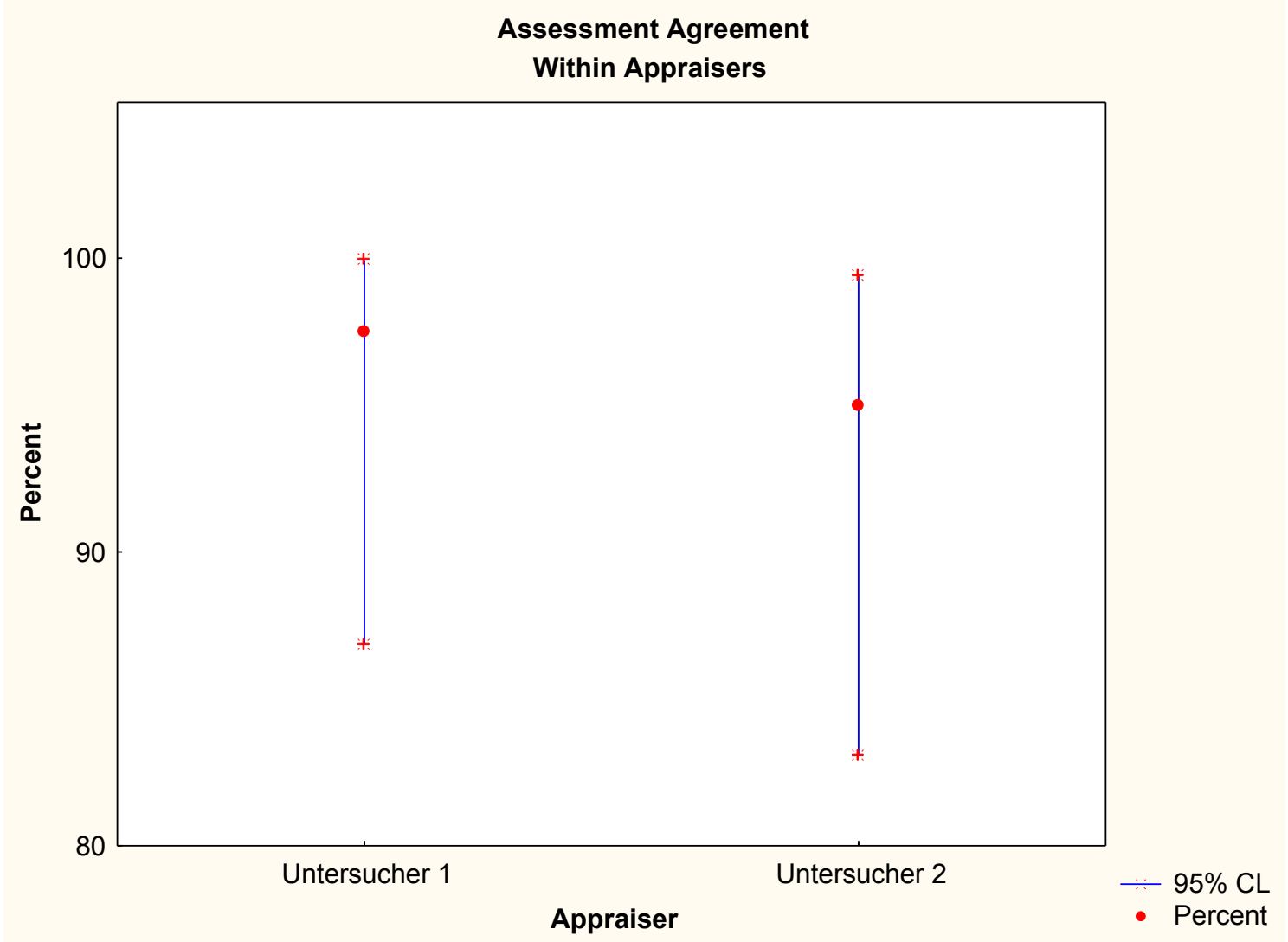

Abbildung 20: Intraindividuelle Übereinstimmung der Untersucher bei wiederholter Bewertung

\subsection{Ergebnisse des Hauptversuches}

Da die Proben mit einem Score-System bewertet wurden und die Daten nicht normalverteilt vorlagen, wurde ein nichtparametrisches Verfahren zur Bestimmung der Signifikanz verwendet. Das Signifikanzniveau wurde auf $\alpha \leq 0,05$ festgelegt.

\subsubsection{Die Vertiefungen in den Wurzelhälften}

Die Art der Vertiefung in den Wurzelhälften (Gruben oder Löcher) zeigte keine signifikante Auswirkung auf die Ergebnisse (Mann-Whitney-U-Test $(p=0,093612)$. Dies bedeutet, dass die Gruben und Löcher gleich gut zu reinigen waren, sodass auf eine getrennte Auswertung dieser beide Gruppen verzichtet und die Ergebnisse zusammengefasst werden konnten. Die Abbildung 21 zeigt die absolute Verteilung der Bewertungen beider Untersucher in Bezug auf die Art der Vertiefung. 


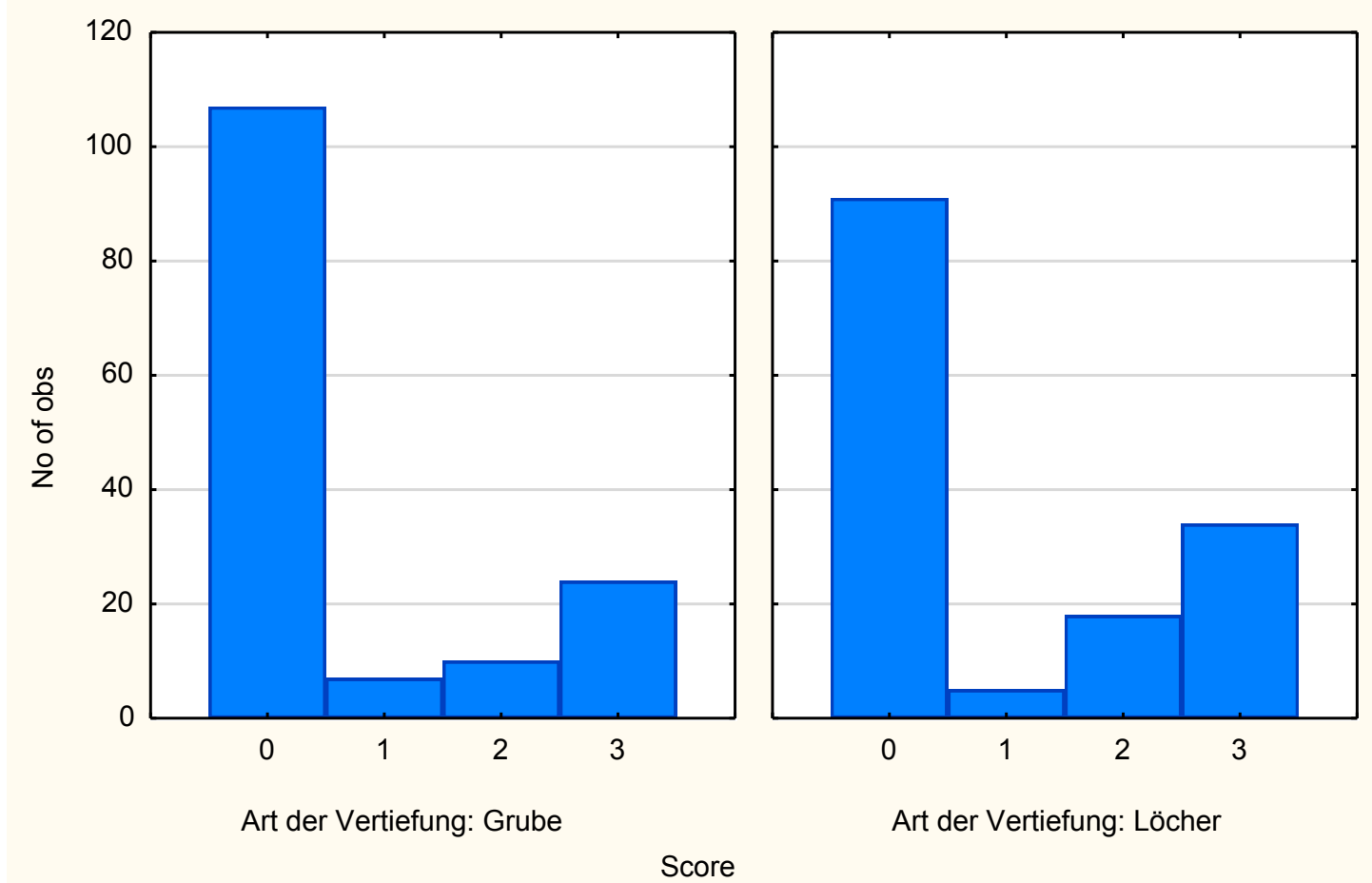

Abbildung 21: Übersicht über die von beiden Untersuchern vergebenen Bewertungen

Der Score 0 wurde für Löcher und Gruben am häufigsten vergeben. Darauf folgten die Scores 3, 2 und 1 in absteigender Reihenfolge.

\subsubsection{Differenzierung zwischen Spültechnik und Spülflüssigkeit}

\subsubsection{Regressionsanalyse}

Anhand der Regressionsanalyse kann eine Vorhersage bezüglich der Variablen Spültechnik, Spülflüssigkeit, Art der Vertiefung und der erzielten Scores getroffen werden. Es ist so möglich, mit diesem Modell die optimale Kombination aus den Variablen des Versuchsaufbaus zu finden. Die Tabelle (siehe Anhang) zeigt diesen Zusammenhang. Es ergibt sich, dass bei einer Verwendung der Komet-Feile SF65 die Kombination aus $\mathrm{NaOCl}$ und Gruben zu dem niedrigsten Score führt $(-0,54864)$. Betrachtet man bei der Regressionsrechnung die Spülflüssigkeit Nanopartikel, so führt die Kombination mit Komet SF65 in Verbindung mit den Gruben am ehesten zu einem niedrigen Score (Regression= 0,45136) . 


\subsubsection{Absolute und relative Häufigkeitsverteilung}

Tabelle 1 zeigt die Verteilung der absoluten Score-Häufigkeiten für die Löcher und Gruben in Bezug auf die verwendete Kombination aus Spültechnik und Spülflüssigkeit.

\begin{tabular}{|l|c|c|c|c|}
\hline Gruppe & Score 0 & Score 1 & Score 2 & Score 3 \\
\hline Komet SF65 + NaOCl & 60 & 0 & 0 & 0 \\
\hline Komet SF65 + Nanopartikel & 51 & 6 & 3 & 0 \\
\hline PUI + NaOCI & 59 & 1 & 0 & 0 \\
\hline PUI + Nanopartikel & 17 & 3 & 12 & 28 \\
\hline Handspülung + NaOCl & 10 & 0 & 8 & 10 \\
\hline Handspülung + Nanopartikel & 1 & 2 & 5 & 20 \\
\hline
\end{tabular}

Tabelle 1: Absolute Häufigkeit der Score-Verteilung für alle Gruppen

Abbildung 22 beschreibt hingegen die relative Häufigkeitsverteilung in Prozent.

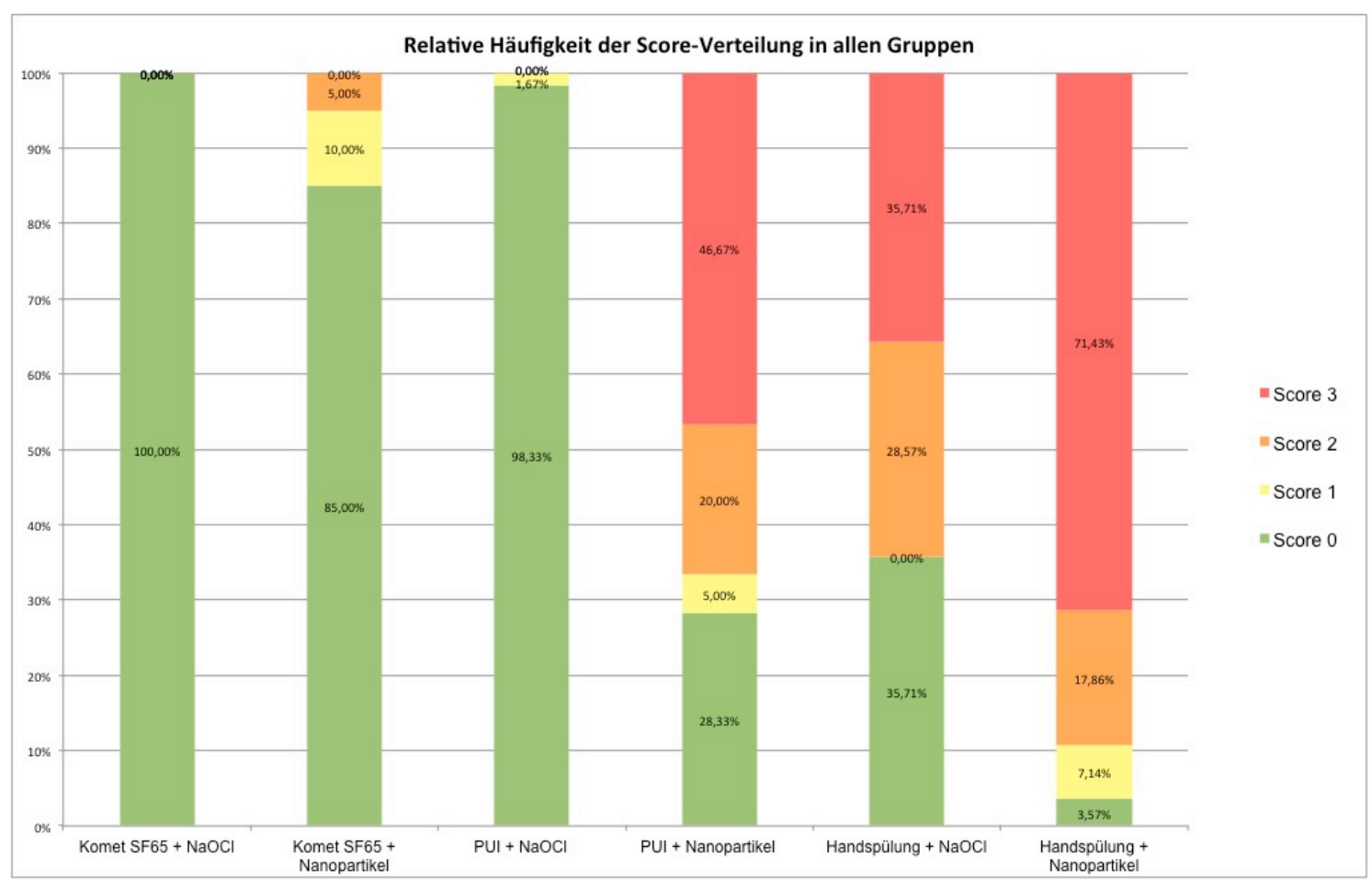

Abbildung 22: Relative Häufigkeit der Score-Verteilung in allen Gruppen 
Der Score 0 konnte in $100 \%$ der Proben für Komet SF65 $+\mathrm{NaOCl}$ erreicht werden, bei Verwendung von Komet SF65 + Nanopartikel in 85\%. Die PUI + $\mathrm{NaOCl}$ lieferte für den Score 0 98,3\%, aber die Gruppe PUI + Nanopartikel konnte nur in $28,3 \%$ der Proben den Score 0 erreichen. Die Handspülung zeigte in Verwendung mit $\mathrm{NaOCl}$ in $35,7 \%$ der Fälle einen Score 0 auf und bei der Handspülung + Nanopartikel in lediglich 3,6\% der Proben.

Der Score 1, d.h. die Gruben oder Löcher sind zwischen 26\% - 50\% mit Debris gefüllt, wurde in der Gruppe Komet SF65 + Nanopartikel in 10\% der Vertiefungen vergeben. In den restlichen Gruppen wurde der Score 1 seltener erzielt.

Die Gruben oder Löcher waren bei PUI + Nanopartikel in 20\% der Bewertungen zu $51 \%-75 \%$ (Score 2) mit Debris gefüllt, bei Handspülung $+\mathrm{NaOCl}$ in $28,6 \%$ und bei Handspülung + Nanopartikel in 17,9\% der Proben.

Score 3 wurde in den Gruppen Komet SF65 $+\mathrm{NaOCl}$, Komet SF65 + Nanopartikel und $\mathrm{PUI}+\mathrm{NaOCl}$ nie vergeben. In den Gruppen $\mathrm{PUI}+$ Nanopartikel wurde der Score 3 in 46,7\% der Proben vergeben, bei Handspülung $+\mathrm{NaOCl}$ in $35,7 \%$ und bei Handspülung + Nanopartikel in $71,4 \%$.

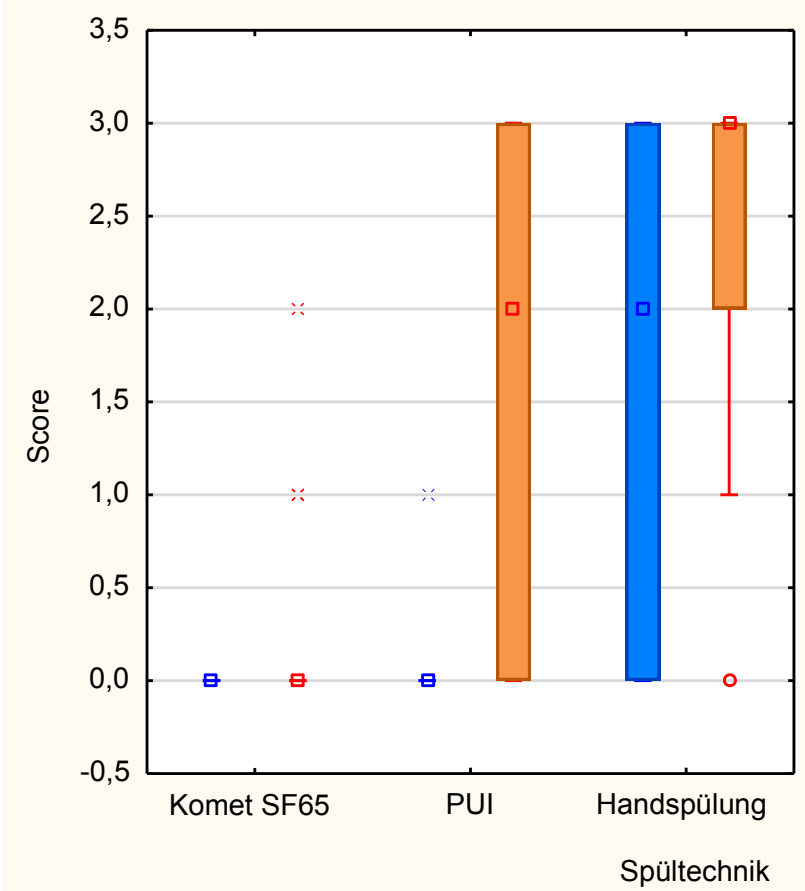

Score/Spülflüssigkeit: $\mathrm{NaOCl}$

Score/Spülflüssigkeit: Nanopartikel

Outliers/Spülflüssigkeit: Nanopartike

Extremes/Spülflüssigkeit: $\mathrm{NaOCl}$

Extremes/Spülflüssigkeit: Nanopartikel

Abbildung 23: Box Plot-Darstellung der verwendeten Spültechnik in Kombination mit den Spülflüssigkeiten 
Diese Ergebnisse werden nochmals in der Box-Plot-Darstellung veranschaulicht (siehe Abbildung 23). Die Mediane der Gruppen Komet SF65 + NaOCl, Komet + Nanopartikel und $\mathrm{PUI}+\mathrm{NaOCl}$ liegen alle bei Score 0 . Es gibt wenige Ausreißer in diesen Gruppen, sodass nur sehr selten ein Score 1 oder 2 vergeben wurde. In den Gruppen PUI + Nanopartikel und Handspülung + $\mathrm{NaOCl}$ wurden alle Score-Bewertungen verteilt. Der Median lag in beiden Gruppen bei Score 2. In der Gruppe Handspülung + Nanopartikel wurde am meisten der Score 3 und Score 2 vergeben. Der Median lag in dieser Gruppe bei Score 3 mit Ausreißern nach Score 1 und Score 0.

\subsubsection{Signifikanzberechnung}

\begin{tabular}{|l|l|c|}
\hline Konstante & Gruppen & Signifikanz $(p)$ \\
\hline $\mathrm{NaOCl}$ & Komet SF65 vs. PUI & 0,876952 \\
\hline Nanopartikel & Komet SF65 vs. PUI & 0,000000 \\
\hline Komet SF65 & $\mathrm{NaOCl} \quad$ vs. Nanopartikel & 0,157214 \\
\hline PUI & $\mathrm{NaOCl} \quad$ vs. Nanopartikel & 0,000000 \\
\hline Handspülung & $\mathrm{NaOCl} \quad$ vs. Nanopartikel & 0,007748 \\
\hline
\end{tabular}

Tabelle 2: Signifikanzen in den Unterschieden zwischen den einzelnen Gruppen

Betrachtet wurden ebenfalls die Unterschiede zwischen den einzelnen Gruppen untereinander. Für $\mathrm{NaOCl}$ bestand kein signifikanter Unterschied zwischen der Aktivierung der Spülflüssigkeit mit der Komet SF65 oder der PUI ( $p=0,876952)$. Bei den Nanopartikeln zeigte sich aber eine deutliche Signifikanz hinsichtlich der verwendeten Spültechnik $(p=0,000000)$. Die Spülspitze Komet SF65 reinigte mit den Nanopartikeln als Spülflüssigkeit die Vertiefungen signifikant besser als die PUI. Betrachtet man jedoch die Spülspitze Komet SF65 in Verwendung mit Nanopartikeln oder $\mathrm{NaOCl}$, zeigte sich kein signifikanter Unterschied zwischen den Spülflüssigkeiten $(p=0,157214)$. Bezogen auf die Spülflüssigkeit zeigte sich bei der PUI eine eindeutige Signifikanz zwischen der Gruppe, die mit Nanopartikeln und mit NaOCl gespült wurde (PUI: p=0,000000). Es konnte bei der Handspülung ein signifikanter Unterschied zwischen den verwendeten Spülflüssigkeiten festgestellt werden (Handspülung: $p=0,007748$ ). 


\subsubsection{Reliabilität der Bewertung des Versuchs}

\begin{tabular}{|r|r|}
\hline Cohen's Kappa Statistics & Kappa \\
\hline Response & 0,938994 \\
\hline 0 & 0,305164 \\
\hline 1 & 0,842302 \\
\hline 2 & 1,000000 \\
\hline 3 & 0,892676 \\
\hline Overall &
\end{tabular}

Tabelle 3: Intraindividuelle Reproduzierbarkeit der Bewertungen der beiden Untersucher

Zur Überprüfung der Verlässlichkeit der Untersucher, die Proben mit demselben Score zu bewerten, wurde der Cohens Kappa-Wert bestimmt. Aufgetrennt nach dem Score-System erhält man für die verschiedenen Bewertungen unterschiedliche Übereinstimmungen. Der Score 0, 2 und 3 wurde mit großer Übereinstimmung vergeben. Der Score 1 (insgesamt zwölfmal von beiden Untersuchern vergeben) hingegen zeigte, dass insbesondere in den Grenzfällen die beiden Untersucher nicht immer in ihrer Bewertung übereingestimmt hatten (Cohens Kappa: 0,305164). Diese Abweichung war allerdings nie größer als ein Score. Auf alle Proben bezogen stimmten die beiden Untersucher in ihren Bewertungen gut überein (Cohens Kappa 0,892676). 


\section{Diskussion}

\subsection{Diskussion der Methode}

Das Studiendesign dieser Studie ist angelehnt an den Versuchsaufbau von Lee et al. (2004a) und van der Sluis et al. (2006). Das Modell wurde bisher verwendet, um Debris (Rödig et al. 2010a; van der Sluis et al. 2010) und auch Kalziumhydroxid (Rödig et al. 2011) aus Vertiefungen zu entfernen. Dabei wurden längliche Gruben oder runde Vertiefungen mit standardisierten Dimensionen im koronalen und apikalen Bereich des Wurzelkanallumens präpariert (Jiang et al. 2011).

Es wurden einwurzelige Zähne mit möglichst geraden Wurzelkanälen verwendet, um vergleichbare Ausgangsbedingungen zwischen den Gruppen herzustellen, dies stellt allerdings nur die einfachste Kanalgeometrie dar. In anderen Versuchen wurden Löcher in gekrümmte Wurzelkanäle präpariert, um auch die Kanalgeometrie von Molaren abzubilden (Amato et al. 2011). In gekrümmten Wurzelkanälen zeigte sich hingegen, dass sich Mikroströmungen nur dann entwickelten, wenn die Utraschallspitzen frei schwingen konnten (Ahmad et al. 1992; van der Sluis et al. 2007a). Da jedoch keine standardisierte Studie zu der Verwendung der Schallspitze Komet SF65 oder den verwendeten Nanopartikeln als Spülflüssigkeit vorlag, wurde ein vergleichbarer Versuchsaufbau gewählt.

Dieses In-vitro-Modell an extrahierten Zähnen bietet darüber hinaus die Möglichkeit, die Bedingungen der Behandlung eines Zahnes möglichst exakt zu simulieren. Versuche an Plastik- oder Titanblöcken können lediglich die Wurzelkanalanatomie grob simulieren (Lee et al. 2004b; Malki et al. 2012; Goode et al. 2013), nicht aber die komplizierten Verhältnisse von Dentin oder Seitenkanälen realistisch abbilden.

Die in dieser Studie verwendeten Vertiefungen in den Wurzelhälften sollen sowohl ovale Kanalbereiche als auch laterale Ausbuchtungen simulieren. Allerdings ist es schwierig, die komplexe Wurzelkanalanatomie durch Vertiefungen widerzuspiegeln (Briseño-Marroquín et al. 2015). Daher könnte es 
einfacher sein, künstlichen Debris aus präparierten Gruben zu entfernen als aus komplexen anatomischen Isthmen, Seitenkanälen und ovalen Kanalabschnitten.

In weiteren In-vitro-Studien wurden Gruben mit Trennscheiben präpariert (Martins Justo et al. 2014) oder Zähne dekalzifiziert, um nachträglich von außen Seitenkanäle zu präparieren (De Gregorio et al. 2010; Castelo-Baz et al. 2012). Die Methode, dekalzifizierte Zähne von außen mit Seitenkanälen zu versehen, bietet zwar die Möglichkeit, die Zähne als Einheit zu belassen, aber durch die Dekalzifizierung werden die Oberflächeneigenschaften von Dentin geändert. Des Weiteren bietet die Verwendung von Tinte zur Visualisierung der Reinigungswirkung nur eine geringe Aussagekraft, da bereits nur geringe Flüssigkeitsbewegungen in einem Seitenkanal sichtbar werden und so einen Einfluss auf das Ergebnis haben könnten. Der Komplexität von Dentindebris in natürlichen Wurzelkanalvertiefungen wird diese Methode nicht gerecht.

In einigen Studien wurden Mikro-Computer-Tomographien eingesetzt, um die Menge entfernter Substanzen auch quantitativ zu bestimmen. Da es bei dieser Methode nicht notwendig ist, das Probenmaterial zu spalten, kann eine sehr genaue Volumenbestimmung des entfernten Materials erfolgen (Paqué et al. 2010; Rödig et al. 2014). Allerdings können so keine standardisierten Vertiefungen in die Wurzelkanäle präpariert werden.

Die Auswertung der gespülten Zahnhälften erfolgte anhand von Fotos. Lee et al. (2004a), van der Sluis et al. (2006b) und Rödig et al. (2010a) verwendeten ähnliche Bewertungssysteme. Die Analyse der Übereinstimmung mit Hilfe von Cohens Kappa-Analyse (globales Ergebnis $=0,892676$ ) verdeutlicht, dass von einer guten Reproduzierbarkeit der Ergebnisse in der vorliegenden Studie ausgegangen werden kann.

Eine Bewertung der Zähne unter einem Mikroskop hätte die dreidimensionale Darstellung der gespülten Gruben verbessert, um eine bessere Einschätzung der Masse des Debris bekommen zu können.

Die in dieser Studie verwendeten Nanopartikel waren zum Zeitpunkt der Versuche noch nie zum Spülen von Wurzelkanälen verwendet worden. Die Nanopartikel liegen in der Flüssigkeit als dicht gepackte Teilchen vor (siehe Abbildungen 1 und 2). Eine optimale Konzentration der festen Bestandteile 
wurde im Rahmen der Versuche nicht ermittelt. Es ist vorstellbar, dass die getesteten Spültechniken mit unterschiedlichen Konzentrationen von Nanopartikeln andere Ergebnisse erzeugen als in dieser Studie. Es wäre also möglich, die vorhandene Flüssigkeit mit Nanopartikeln zu zentrifugieren, um anschließend aus den festen Bestandteilen unterschiedlich konzentrierte Spülflüssigkeiten herzustellen.

Der künstlich hergestellte Debris ließ sich verhältnismäßig gut aus den Gruben und Löchern entfernen. Eine Verwendung von schwieriger zu entfernenden Substanzen wie Kalziumhydroxid würde zeigen können, ob mit Nanopartikeln die Vertiefungen besser zu reinigen wären als mit bisher angewendeten Methoden.

In dieser Studie wurden pro Hauptgruppe n=15 Zähne und für die Kontrollgruppen $n=7$ Zähne verwendet. Diese Gruppengrößen finden sich auch bei anderen Autoren wieder (van der Sluis et al. 2005b; van der Sluis et al. 2006b; Jiang et al. 2011; Malki et al. 2012; Alkahtani et al. 2014).

\subsection{Diskussion der Ergebnisse}

Die drei verwendeten Spültechniken waren unterschiedlich effizient in der Beseitigung von Debris aus den Vertiefungen. Die Verwendung von Schall oder Ultraschall in Verbindung mit $\mathrm{NaOCl}$ lieferte gleich gute Ergebnisse. Die Nanopartikel erzielten lediglich in Kombination mit einer schallaktivierten Spülung gut gereinigte Gruben und Löcher. Mit Ultraschall aktivierte Nanopartikel erbrachten deutlich schlechtere Ergebnisse. Nur die Handspülung erzielte noch schlechtere Ergebnisse bei Verwendung der Nanopartikel.

Die Ergebnisse fielen für die Gruben geringfügig besser aus als für die Löcher, aber der Unterschied war nicht signifikant ( $p=0,093612$ ). Das bestätigt die Ergebnisse von Lee et al. (2004). Bei Rödig et al. (2010) ließen sich die Gruben jedoch statistisch signifikant besser reinigen als die Löcher. Rödig et al. (2010) vermuteten, dass die größere Oberfläche der Gruben, die zum Lumen des Wurzelkanals gerichtet ist, eine bessere Angriffsfläche für hydrodynamische Effekte zur Entfernung von Debris bietet. 


\subsubsection{Reinigungswirkung der Komet SF65}

Die Reinigungswirkung der Schallspitze Komet SF65 wurde bisher in keiner Studie untersucht.

Mit der SF65 konnten in dieser Studie die besten Ergebnisse sowohl mit $\mathrm{NaOCl}$ als auch mit Nanopartikeln erzielt werden. In der Gruppe Komet SF65 + NaOCl waren sowohl die Gruben als auch die Löcher in allen Fällen sauber und erreichten durchgehend den Score 0. In der Gruppe Komet SF65 + Nanopartikel fielen die Ergebnisse ebenfalls zufriedenstellend aus.

Es werden zum gegenwärtigen Zeitpunkt mehrere schallaktivierte Spülsysteme angeboten. Der EndoActivator (Dentsply, Tulsa, USA) wurde bislang am häufigsten untersucht. Deshalb bietet es sich an, die Ergebnisse der Komet SF65 mit den Ergebnissen des schallbasierten EndoActivators zu vergleichen. Der EndoActivator besteht aus einem batteriebetriebenen Handstück, das Schallwellen auf verschieden große Kunststoffspitzen überträgt. Der Hersteller empfiehlt die Spültechnik zur abschließenden Wurzelkanalspülung unter Einsatz von Spitzen, die der abschließenden Präparationsgröße entsprechen. Bei der Entfernung von smear layer erreichte der EndoActivator sowohl in geraden als auch in gekrümmten Kanälen eine deutlich bessere Reinigung als die PUI oder die CanalBrush (Rödig et al. 2010b; Mancini et al. 2013). Bei der Entfernung von Debris wurde kein Unterschied zwischen Schall-, Ultraschalloder Handspülungen festgestellt (Klyn et al. 2010; Bolles et al. 2013). Auch die Untersuchung von Jensen et al. (1999) ergab, dass nach der Präparation des Wurzelkanals und anschließender Spülung des Wurzelkanallumens kein Unterschied in der Entfernung von Debris zwischen EndoActivator und PUI vorlag. Bei Paragliola et al. (2010) erzielte jedoch die PUI eine bessere Penetration der Dentinkanäle als der EndoActivator (Paragliola et al. 2010). Hingegen untersuchten Kanter et al. (2011) an einwurzeligen Eckzähnen ebenfalls die Entfernung von Debris an bereits präparierten Wurzelkanälen und beschrieben eine signifikante Überlegenheit des EndoActivator gegenüber der PUI.

Der EndoActivator wurde auch in dem in dieser Studie verwendeten Grubenmodell mit anderen Spültechniken verglichen. Arslan et al. (2014) fanden keinen Unterschied zwischen der Passive Ultrasonic Irrigation (PUI) und 
dem schallbasierten EndoActivator bei der Entfernung von Debris aus zwei apikal gelegenen Gruben. Die Ergebnisse fielen allerdings wesentlich schlechter aus als in der vorliegenden Studie. Arslan et al. (2014) verwendeten zur Spülung allerdings $1 \%$ iges $\mathrm{NaOCl}$ und spülten für 60 Sekunden mit $25 \%$ der verfügbaren Leistung eines Ultraschallgenerators (PUI). Durch die Zugangskavität wurden über diese Zeit $5,5 \mathrm{ml} \mathrm{NaOCl}$ hinzugefügt. Es ist möglich, dass diese Abweichungen von dem in dieser Studie verwendeten Spülprotokoll zu den deutlich schlechteren Ergebnissen geführt haben. Durch das Einbringen von Spülflüssigkeit durch die Zugangskavität könnte eine große Luftblase entstanden sein (Vapor-Lock Effekt), die es dem EndoActivator und der PUI nicht ermöglichten, die Wurzelkanäle vergleichbar zu reinigen.

Da der EndoActivator die Energie über Polymerspitzen überträgt, ist ein Vergleich mit der Komet-Spitze SF65 nur bedingt möglich.

Die physikalischen Eigenschaften von Schallinstrumenten unterscheiden sich nicht wesentlich von denen der Ultraschallspitzen. Lediglich die Schwingungsfrequenz der Spitze führt zu unterschiedlichen mikrodynamischen Strömungsmustern. Die Schallspitze bringt Flüssigkeit durch einen Schwingungsbauch und ein Schwingungstal in Bewegung und es entstehen wie bei der ultraschallaktivierten Spülung Kavitationen. Die Vermutung liegt nahe, dass die entstehenden Mikrobläschen größer sind als die Nanopartikel, sodass die kinetische Energie ausreicht, um die Nanopartikel anzustoßen. Weitere Untersuchungen müssen zeigen, wie genau die Strömungsmuster und die entstehenden Mikrobläschen aussehen und zusammenhängen, um die Spülspitze Komet SF65 zu bewerten. In Verbindung mit $\mathrm{NaOCI}$ hinterließ die Komet SF65 die saubersten Vertiefungen in den Zähnen.

\subsubsection{Reinigungswirkung der PUI}

Die Ergebnisse der Passive Ultrasonic Irrigation (PUI) fielen in der Gruppe mit $\mathrm{NaOCl}$ ähnlich gut aus wie die der schallaktivierten Spülspitze Komet SF65 in Verbindung mit $\mathrm{NaOCl}$.98,3\% der Proben erzielten einen Score 0. Lediglich in einer Bewertung wurde ein Score 1 vergeben (1,7\%). Diese Ergebnisse bestätigen die Resultate anderer Studien bezüglich der Reinigungsleistung der PUI (van der Sluis et al. 2010; Rödig et al. 2010c). Auch bei Lee et al. (2004) erzielte die PUI im Vergleich zur Handspülung die besten Ergebnisse. Die 
Studie von Lee et al. stellt die erste Studie dieser Art dar, in der künstliche Gruben in Wurzelkanalhälften präpariert wurden, um anschließend die mit Debris gefüllten Zähne zu spülen.

Eine abgewandelte Studie überprüfte ebenfalls die Entfernung von Debris aus einer apikalen und einer koronal gelegenen Grube (Rödig et al. 2010a). Abermals stellte sich heraus, dass die PUI gegenüber der Handspülung die saubersten Vertiefungen in Verwendung mit $\mathrm{NaOCl}$ hinterließ. Die Ergebnisse von Rödig et al. (2010a) zeigten mit 92,5\% ermittelten Score 0 Bewertungen ein vergleichbar gutes Ergebnis wie in dieser Studie.

Oft wurde festgestellt, dass sich die Gruben und Löcher in geraden Wurzelkanälen gut zur Standardisierung eignen, aber die komplexe Wurzelkanalanatomie jedoch nicht wiederspiegeln. In gekrümmten Wurzel-kanälen von Molaren zeigte sich, dass im Vergleich zu geraden Wurzelkanälen die PUI trotzdem saubere Wurzelkanäle hinterlässt (Amato et al. 2011). Es sollte jedoch darauf geachtet werden, dass in gekrümmten Kanälen die Spülspitze frei schwingen kann, da sonst keine akustische Mikroströmungen generiert werden (van der Sluis et al. 2007a).

Der Versuchsaufbau von Lee et al. (2004) verwendete extrahierte Zähne, um die Oberflächeneigenschaften von Dentin zu berücksichtigen. Weller et al. (1980) zeigten jedoch keinen signifikanten Unterschied zwischen Plastikblöcken und extrahierten Zähnen bei der Verwendung der PUI. Lee et al. (2004b) und van der Sluis et al. (2005) untersuchten daher ultraschallaktivierte Spültechniken an Wurzelkanalmodellen aus Plastik. Es wurde kein Unterschied zwischen der Verwendung einer K-Feile und eines weichen Drahtes in der Entfernung von Dentindebris festgestellt (van der Sluis et al. 2005a). Beide Ultraschallspitzen säuberten die Vertiefungen gleich gut. Van der Sluis et al. (2007a) fordern daher, dass eine Ultraschallspitze frei im flüssigkeitsgefüllten Wurzelkanal schwingen sollte, da sie nur so die maximale Reinigungsleistung erzielt.

In einem anderen Versuchsdesign wurde in extrahierten Zähnen die Entfernung von Debris bestimmt, ohne Vertiefungen in die Kanalwände zu präparieren (Sabins et al. 2003; Rödig et al. 2010b). Dieses Modell spiegelt die klinische Realität zwar besser wieder, ist aber nicht standardisierbar. Die Ergebnisse von 
Rödig et al. (2010b) zeigen daher auch, dass es keinen Unterschied zwischen den Gruppen der Schall- oder Ultraschallspülung gab, aber eine Überlegenheit im Vergleich zur Spülung mit der Spritze ohne zusätzliche Aktivierung der Spülflüssigkeit festzustellen war. Sabins et al. (2003) fanden jedoch im direkten Vergleich zwischen Schall- und Ultraschallspülung einen signifikanten Unterschied. Die passive Ultraschallspülung säuberte die Wurzelkanalwände besser. Die schallaktivierte Spülung erfolgte mit einer Rispisonic Feile.

Einige Studien untersuchten die Entfernung von Kalziumhydroxid aus präparierten Gruben. Kalziumhydroxid wird als medikamentöse Einlage bei Parodontitis apicalis verwendet, um die Keimzahl zu reduzieren. Nach der Applikation von Kalziumhydroxid erhärtet dieses und ist dadurch schwieriger zu entfernen. Die PUI zeigte deutlich besser gereinigte Gruben als die Handspülung. Der wesentliche Faktor war jedoch die Verwendung von $\mathrm{NaOCl}$ als Spülmedium, da ein statistisch signifikanter Unterschied zwischen der Ultraschallspülung mit Wasser und $\mathrm{NaOCI}$ gefunden wurde (van der Sluis et al. 2007b). Rödig et al. (2011) fanden bei der Entfernung von Kalziumhydroxid aus Gruben keinen Unterschied zwischen der PUI und RinsEndo.

Eine andere Methode zur Bestimmung der Reinigungswirkung verschiedener Spültechniken stellt die Dekalzifizierung und anschließende Präparation von Seitenkanälen von außerhalb in den Zahn dar. Castelo-Baz et al. (2012) zeigten in ihrer Studie, dass auch hier die passive Ultraschallspülung gegenüber der klassischen Handspülung mehr Seitenkanäle reinigen konnte. In 30\% der gespülten Zähne erreichte Tinte, die als Spüllösung verwendet wurde, Seitenkanäle im apikalen Drittel eines Zahnes. Die Handspülung schaffte dieses in keinem einzigen Fall. Nur die continuous ultrasonic irrigation erreichte $67 \%$ gespülte Seitenkanäle. Dieses gute Ergebnis ist allerdings damit zu erklären, dass bei Verwendung von Tinte als Spüllösung Spültechniken mit einer kontinuierlichen Flüssigkeitszufuhr generell bessere Resultate erbringen, weil bereits wenige Farbpartikel, die in die Seitenkanäle eindringen, dort sichtbar sind und für die Bewertung verbleiben.

Die histologischen Untersuchungen von Gutarts et al. (2005) und Vinhorte et al. (2014) zeigten an gekrümmten Molarenwurzeln und an Unterkieferinzisivi die Entfernung von Debris aus nicht instrumentierten Bereichen des Wurzelkanals. 
Beide stellten fest, dass bei Verwendung der Ultraschallspülung signifikant mehr Debris entfernt wurde als mit anderen Spültechniken.

Die in der vorliegenden Studie verwendeten Nanopartikel wurden bisher nicht zur ultraschallaktivierten Spülung von Wurzelkanälen verwendet. Die Ergebnisse dieser Studie zeigen einen signifikanten Unterschied zwischen den mit $\mathrm{NaOCl}$ oder Nanopartikeln gespülten Wurzelkanälen. Die Ultraschallspülung mit Nanopartikeln unterlag der Ultraschallspülung mit $\mathrm{NaOCl}$ signifikant $(p=0,000000)$.

Die deutlich schlechtere Reinigungswirkung der PUI in Kombination mit Nanopartikeln kann auf unterschiedliche Faktoren zurückgeführt werden. Die bei der Ultraschallaktivierung entstehenden Mikrobläschen könnten deutlich kleiner sein als die Nanopartikel, sodass die für die Kavitationseffekte verantwortlichen Bläschen keine ausreichende Energie zur Aktivierung der Nanopartikel aufweisen. Die Viskosität der Nanopartikel ist deutlich höher als die von $\mathrm{NaOCl}$. Theoretisch tritt auch in hochviskösen Flüssigkeiten Kavitation auf, die auftretenden Mikrobläschen könnten aber von den viskösen Nanopartikeln gedämpft werden. Die Partikelgröße des Debris könnte ebenfalls einen Einfluss auf die Entfernbarkeit haben.

Weitere Untersuchungen zu diesen Variablen müssen den genauen Zusammenhang zwischen den Nanopartikeln und den auftretenden Strömungsmustern der PUI klären.

Walmsley et al. (2013) zeigten durch Visualisierung von Kavitationen mit Hilfe der Biolumineszenz das Ausmaß der Mikrobläschen. Ähnliche Untersuchungen wären als Nachweis von Kavitationen in den Nanopartikeln anzustreben, um die Wirkung des Ultraschalls zu untersuchen. Insgesamt zeigt die Ultraschallspülung in Kombination mit $\mathrm{NaOCl}$ eine sehr gute Reinigungswirkung. Die Feile sollte frei schwingen, sodass Schwingungsknoten ungehindert entstehen können. $\mathrm{NaOCl}$ verstärkt den Effekt der Reinigung des Wurzelkanalsystems und ist der konventionellen Handspülung überlegen.

\subsubsection{Reinigungswirkung der Handspülung}

Die Handspülung diente als Kontrollgruppe und wurde mit beiden Spülflüssigkeiten verwendet. Die Handspülung stellt die geläufigste Methode der 
Applikation einer Spülflüssigkeit in einen Wurzelkanal dar. Die stumpfe Kanüle transportiert das Spülmedium ca. 1-2 mm über die Spülspitze hinaus. Die Strömungsmuster sind abhängig von der Größe der Kanüle und auf das Ende der Kanüle begrenzt (Chow 1983). Die Nanopartikel in Kombination mit der Handspülung lieferten die schlechtesten Ergebnisse in dieser Studie. In 71,4\% der Fälle wurde ein Score 3 ermittelt. Die Nanopartikel waren also nicht in der Lage, die Vertiefungen ausreichend zu säubern.

Die Handspülung wurde in vielen Studien als Vergleichsgruppe verwendet, da sie eine einfache Methode darstellt, eine Spülflüssigkeit zu transportieren. Die Ergebnisse der Gruppe Handspülung + $\mathrm{NaOCl}$ ähneln den Ergebnissen von Lee et al. (2004a), die die ultraschallaktivierte Spülung mit der Handspülung verglichen. Um erfolgreich Debris und den smear layer aus dem apikalen Kanaldrittel zu entfernen, ist eine Präparationsgröße von mindestens ISO 30 erforderlich (Khademi et al. 2006). Bei Rödig et al. (2010a,c) waren die Ergebnisse der Handspülung im Vergleich zu mehreren aktivierten Spültechniken schlechter als in der hier vorliegenden Studie.

Histologische Untersuchungen an Molaren zeigten, dass ein erfolgreiches Debridement nur erreicht wird, wenn die Handspülung mit weiteren Spültechniken kombiniert wird (Gutarts et al. 2005).

Die Methode der Handspülung mit Spritze und Kanüle ist jedoch anfällig für Anwendungsfehler. Die Fließrate ist der maßgebende Faktor für die Effektivität der Handspülung (Boutsioukis et al. 2007). Castelo-Baz et al. (2012) erkannten, dass eine genaue Positionierung der Spülkanüle wichtig ist, da in einem größeren Abstand als $2 \mathrm{~mm}$ vor der Arbeitslänge die dynamischen Strömungsmuster nicht ausreichten, um den Wurzelkanal vollständig zu reinigen.

Zusammenfassend lässt sich festhalten, dass die Spülung von Wurzelkanälen mit einer Spritze und Kanüle eine verbreitete Methode darstellt, während der Präparation die Spülflüssigkeit im Wurzelkanal auszutauschen. Hinsichtlich der Entfernung von Debris aus Vertiefungen liefert diese Spültechnik keine zufriedenstellenden Ergebnisse. Die Nanopartikel stellten für die Spültechnik sogar eine größere Hürde dar als konventionelles $\mathrm{NaOCl}$. Hier ist wahrscheinlich die hohe Viskosität der Nanopartikel für die schlechteren Ergebnisse verantwortlich. 


\section{Zusammenfassung}

Ziel der Studie: Untersucht wurde die Entfernung von Debris aus präparierten Vertiefungen in der Wurzelkanalwand extrahierter Zähne mit ultraschall- und schallaktivierter Spülung. Als Spüllösungen wurden Natriumhypochlorit und Nanopartikel verwendet.

Material und Methode: Es wurden 74 extrahierte, einwurzelige Zähne in sechs Gruppen (4 Hauptgruppen mit je 15 Zähnen und 2 Kontrollgruppen mit je 7 Zähnen) aufgeteilt. Die Zähne wurden auf eine Länge von $19 \mathrm{~mm}$ gekürzt und mit Nickel-Titan-Instrumenten maschinell auf eine Größe von ISO 40/.04 mit einer Arbeitslänge von $18 \mathrm{~mm}$ präpariert. Nach jeder Instrumentengröße wurde mit jeweils $2 \mathrm{ml} 3 \%$ igem Natriumhypochlorit mit einer Handspritze und 30 Gauge-Kanüle gespült. Die Abschlussspülung erfolgte mit 5 ml EDTA (17\%) und $5 \mathrm{ml} \mathrm{NaOCl}$ (3\%). Mit einer Trennscheibe wurden die Zähne eingekerbt und longitudinal in zwei Zahnwurzelhälften gespalten. Anschließend wurde in jede Wurzelhälfte entweder eine Grube von $4 \mathrm{~mm}$ Länge oder 3 Löcher von 0,3 mm Durchmesser in die apikalen Anteile der Wurzelkanäle präpariert. Die Vertiefungen wurden mit Debris gefüllt und wieder zusammengesetzt. Die anschließende Spülung erfolgte mit der schallaktivierten Komet SF65-Spülfeile und der ultraschallaktivierten Acteon IrriSafe-Spülnadel der Größe ISO 20 jeweils mit Natriumhypochlorit und Nanopartikeln. Die Ultraschall- und Schallspitze wurden in jeweils 3 Spülzyklen zu je 20 Sekunden aktiviert. Die Handspülung mit Spritze und Kanüle der Größe 30 diente als Spültechnik für die Kontrollgruppen. Es wurde hier mit $10 \mathrm{ml}$ Spülflüssigkeit gespült. Die Zähne wurden anschließend wieder getrennt und anhand von Fotografien von zwei Untersuchern anhand eines vierstufigen Score-Systems bewertet. Die statistische Auswertung erfolgte mit einem nichtparametrischen Analyseverfahren.

Ergebnis: Sowohl die ultraschall- als auch die schallaktivierte Spülspitze war in der Lage, mit Natriumhypochlorit alle oder fast alle Vertiefungen sehr gut zu reinigen. Die Nanopartikel reinigten lediglich in der Gruppe der schallbasierten 
Spülung die Vertiefungen ausreichend gut. Die Handspülung lieferte keine zufriedenstellenden Ergebnisse.

Schlussfolgerung: Die Aktivierung von Natriumhypochlorit ist sowohl mit der schall- als auch der ultraschallbasierten Spülspitze sehr gut geeignet, Debris aus Vertiefungen zu entfernen. Die Nanopartikel lieferten lediglich in der Schallgruppe gute Ergebnisse und konnten die Gruben und Löcher gut säubern. Die Nanopartikel sollten weiter erforscht werden, um eine ideale Partikelgröße und Partikelkonzentration für unterschiedliche Spültechniken zu finden. 


\section{Anhang}

\begin{tabular}{|c|c|c|c|c|c|}
\hline & \multicolumn{3}{|c|}{ Untersucher 1} & \multicolumn{2}{|c|}{ Untersucher 2} \\
\hline & $\begin{array}{l}\text { Proben- } \\
\text { nummer }\end{array}$ & Gruben & Löcher & Gruben & Löcher \\
\hline \multirow[t]{5}{*}{ Komet $+\mathrm{NaOCl}$} & 1 & 0 & 0 & 0 & 0 \\
\hline & 2 & 0 & 0 & 0 & 0 \\
\hline & 3 & 0 & 0 & 0 & 0 \\
\hline & 4 & 0 & 0 & 0 & 0 \\
\hline & 5 & 0 & 0 & 0 & 0 \\
\hline \multirow[t]{5}{*}{ Komet + Nano } & 6 & 0 & 1 & 0 & 0 \\
\hline & 7 & 2 & 1 & 1 & 1 \\
\hline & 8 & 1 & 0 & 1 & 0 \\
\hline & 9 & 0 & 2 & 0 & 2 \\
\hline & 10 & 0 & 0 & 0 & 0 \\
\hline \multirow[t]{5}{*}{$\mathrm{PUI}+\mathrm{NaOCl}$} & 11 & 0 & 0 & 0 & 0 \\
\hline & 12 & 0 & 0 & 0 & 0 \\
\hline & 13 & 0 & 0 & 0 & 0 \\
\hline & 14 & 0 & 0 & 0 & 0 \\
\hline & 15 & 0 & 0 & 0 & 0 \\
\hline \multirow[t]{5}{*}{ PUI + Nano } & 16 & 2 & 2 & 2 & 2 \\
\hline & 17 & 2 & 0 & 1 & 0 \\
\hline & 18 & 3 & 3 & 3 & 3 \\
\hline & 19 & 3 & 3 & 3 & 3 \\
\hline & 20 & 3 & 0 & 3 & 0 \\
\hline \multirow[t]{5}{*}{ Komet + $\mathrm{NaOCl}$} & 21 & 0 & 0 & 0 & 0 \\
\hline & 22 & 0 & 0 & 0 & 0 \\
\hline & 23 & 0 & 0 & 0 & 0 \\
\hline & 24 & 0 & 0 & 0 & 0 \\
\hline & 25 & 0 & 0 & 0 & 0 \\
\hline \multirow[t]{5}{*}{ Komet + Nano } & 26 & 0 & 0 & 0 & 0 \\
\hline & 27 & 0 & 0 & 0 & 0 \\
\hline & 28 & 0 & 0 & 0 & 0 \\
\hline & 29 & 0 & 0 & 0 & 0 \\
\hline & 30 & 0 & 0 & 0 & 0 \\
\hline \multirow[t]{3}{*}{$\mathrm{PUI}+\mathrm{NaOCl}$} & 31 & 0 & 0 & 0 & 0 \\
\hline & 32 & 0 & 0 & 0 & 0 \\
\hline & 33 & 0 & 0 & 0 & 0 \\
\hline
\end{tabular}




\begin{tabular}{|c|c|c|c|c|c|}
\hline & 34 & 0 & 1 & 0 & 0 \\
\hline & 35 & 0 & 0 & 0 & 0 \\
\hline \multirow[t]{5}{*}{ PUI + Nano } & 36 & 3 & 0 & 3 & 0 \\
\hline & 37 & 0 & 3 & 0 & 3 \\
\hline & 38 & 0 & 3 & 0 & 3 \\
\hline & 39 & 3 & 1 & 3 & 0 \\
\hline & 40 & 0 & 2 & 0 & 2 \\
\hline \multirow[t]{5}{*}{ Komet $+\mathrm{NaOCl}$} & 41 & 0 & 0 & 0 & 0 \\
\hline & 42 & 0 & 0 & 0 & 0 \\
\hline & 43 & 0 & 0 & 0 & 0 \\
\hline & 44 & 0 & 0 & 0 & 0 \\
\hline & 45 & 0 & 0 & 0 & 0 \\
\hline \multirow[t]{5}{*}{ Komet + Nano } & 46 & 0 & 0 & 0 & 0 \\
\hline & 47 & 0 & 0 & 0 & 0 \\
\hline & 48 & 0 & 0 & 0 & 0 \\
\hline & 49 & 0 & 0 & 0 & 0 \\
\hline & 50 & 0 & 0 & 0 & 0 \\
\hline \multirow[t]{5}{*}{$\mathrm{PUI}+\mathrm{NaOCl}$} & 51 & 0 & 0 & 0 & 0 \\
\hline & 52 & 0 & 0 & 0 & 0 \\
\hline & 53 & 0 & 0 & 0 & 0 \\
\hline & 54 & 0 & 0 & 0 & 0 \\
\hline & 55 & 0 & 0 & 0 & 0 \\
\hline \multirow[t]{5}{*}{ PUI + Nano } & 56 & 0 & 2 & 0 & 2 \\
\hline & 57 & 0 & 3 & 0 & 3 \\
\hline & 58 & 3 & 2 & 3 & 2 \\
\hline & 59 & 2 & 3 & 1 & 3 \\
\hline & 60 & 3 & 3 & 3 & 3 \\
\hline \multirow[t]{7}{*}{$\begin{array}{l}\text { Handspülung + } \\
\mathrm{NaOCl}\end{array}$} & 61 & 3 & 2 & 3 & 2 \\
\hline & 62 & 0 & 3 & 0 & 3 \\
\hline & 63 & 3 & 2 & 3 & 2 \\
\hline & 64 & 0 & 3 & 0 & 3 \\
\hline & 65 & 0 & 3 & 0 & 3 \\
\hline & 66 & 0 & 2 & 0 & 2 \\
\hline & 67 & 0 & 2 & 0 & 2 \\
\hline \multirow[t]{7}{*}{$\begin{array}{l}\text { Handspülung + } \\
\text { Nano }\end{array}$} & 68 & 3 & 3 & 3 & 3 \\
\hline & 69 & 3 & 3 & 2 & 3 \\
\hline & 70 & 3 & 3 & 3 & 3 \\
\hline & 71 & 2 & 3 & 2 & 3 \\
\hline & 72 & 0 & 3 & 1 & 3 \\
\hline & 73 & 2 & 3 & 2 & 3 \\
\hline & 74 & 1 & 3 & 2 & 3 \\
\hline
\end{tabular}




\begin{tabular}{|c|c|c|c|c|c|c|}
\hline \multirow[b]{2}{*}{$\mathrm{N}=296$} & \multicolumn{6}{|c|}{$\begin{array}{l}\text { Regression Summary for Dependent Variable: Score für Regression) } \\
R=, 72731580 R^{2}=, 52898827 \text { Adjusted } R^{2}=, 52251388 \\
F(4,291)=81,705 p<0,0000 \text { Std.Error of estimate: }, 85169\end{array}$} \\
\hline & \begin{tabular}{|c|}
$b^{*}$ \\
\end{tabular} & $\begin{array}{l}\text { Std.Err. } \\
\text { of b* }^{*}\end{array}$ & $b$ & $\begin{array}{l}\text { Std.Err. } \\
\text { of b }\end{array}$ & $\mathrm{t}(291)$ & $p$-value \\
\hline Intercept & & & 3,16120 & 0,238880 & 13,2334 & 0,000000 \\
\hline Spültechnik1 & $-0,800882$ & 0,054997 & $-2,00714$ & 0,137833 & $-14,5622$ & 0,000000 \\
\hline Spültechnik2 & $-0,46836 \mathrm{c}$ & 0,054997 & $-1,17381$ & 0,137833 & $-8,5162$ & 0,000000 \\
\hline Spülflüssigkeit & $-0,406354$ & 0,040232 & $-1,00000$ & 0,099007 & $-10,1003$ & 0,000000 \\
\hline Art der Vertiefung & 0,120808 & 0,040232 & 0,29730 & 0,099007 & 3,0028 & 0,002907 \\
\hline
\end{tabular}

Tabelle 5: Regressionstabelle: Komet SF65 = 1, PUI = 2, Handspülung = 3, Nanopartikel = 1, $\mathrm{NaOCl}=2$, Gruben $=1$, Löcher $=2$ 


\section{$9 \quad$ Literaturverzeichnis}

Abou-Rass M, Piccinino MV (1982): The effectiveness of four clinical irrigation methods on the removal of root canal debris. Oral Surg Oral Med Oral Pathol 54, 323-328

Acteon IrriSafe - Passive Ultraschallspülung, aktive Desinfektion. Mettmann 2011

http://de.acteongroup.com/out/pictures/DownloadHandler/Files//rriSafe_Prosp_ R3.pdf [Zugriff am 27.7.2016].

Ahmad M (1990): Measurements of temperature generated by ultrasonic file in vitro. Dent Traumatol 6, 230-231

Ahmad M, Pitt Ford TR, Crum LA (1987): Ultrasonic debridement of root canals: an insight into the mechanisms involved. J Endod 13, 93-101

Ahmad M, Roy RA, Kamarudin AG (1992): Observations of acoustic streaming fields around an oscillating ultrasonic file. Endod Dent Traumatol 8, 189-194

Aktener BO, Cengiz T, Pişkin B (1989): The penetration of smear material into dentinal tubules during instrumentation with surface-active reagents: a scanning electron microscopic study. J Endod 15, 588-590

Alkahtani A, Al Khudhairi TD, Anil S (2014): A comparative study of the debridement efficacy and apical extrusion of dynamic and passive root canal irrigation systems. BMC Oral Health 14, 12

Amato M, Vanoni-Heineken I, Hecker H, Weiger R (2011): Curved versus straight root canals: the benefit of activated irrigation techniques on dentin debris removal. Oral Surg Oral Med Oral Pathol Oral Radiol Endod 111, 529_ 534

Arslan H, Capar ID, Saygili G, Gok T, Akcay M (2014): Effect of photon-initiated photoacoustic streaming on removal of apically placed dentinal debris. Int Endod J 47, 1072-1077

Baker NA, Eleazer PD, Averbach RE, Seltzer S (1975): Scanning electron 
microscopic study of the efficacy of various irrigating solutions. J Endod 1, 127135

BASF AG (2002): Journalisten und Wissenschaftler im Gespräch Nanotechnologie in der Chemie - Experience meets Vision o.O.

Bolles JA, He J, Svoboda KKH, Schneiderman E, Glickman GN (2013): Comparison of Vibringe, EndoActivator, and Needle Irrigation on Sealer Penetration in Extracted Human Teeth. J Endod 39, 708-711

Boutsioukis C, Lambrianidis T, Kastrinakis E, Bekiaroglou P (2007): Measurement of pressure and flow rates during irrigation of a root canal ex vivo with three endodontic needles. Int Endod J 40, 504-513

Boutsioukis C, Gogos C, Verhaagen B, Versluis M, Kastrinakis E, Van der Sluis LWM (2010a): The effect of apical preparation size on irrigant flow in root canals evaluated using an unsteady Computational Fluid Dynamics model: CFD preparation size study. Int Endod J 43, 874-881

Boutsioukis C, Gogos C, Verhaagen B, Versluis M, Kastrinakis E, Van der Sluis LWM (2010b): The effect of root canal taper on the irrigant flow: evaluation using an unsteady Computational Fluid Dynamics model: CFD canal taper study. Int Endod J 43, 909-916

Brännström M, Johnson G (1974): Effects of various conditioners and cleaning agents on prepared dentin surfaces: a scanning electron microscopic investigation. J Prosthet Dent 31, 422-430

Braun A, Krause F, Nolden R, Frentzen M (2003): Subjective intensity of pain during the treatment of periodontal lesions with the Vector-system. J Periodontal Res $\underline{38}, 135-140$

Braun A, Krause F, Frentzen M, Jepsen S (2005): Efficiency of subgingival calculus removal with the Vectortm-system compared to ultrasonic scaling and hand instrumentation in vitro. J Periodontal Res 40 , 48-52

Briseno BM, Wirth R, Hamm G, Standhartinger W (1992): Efficacy of different irrigation methods and concentrations of root canal irrigation solutions on bacteria in the root canal. Endod Dent Traumatol $\underline{8}, 6-11$

Briseño-Marroquín B, Paqué F, Maier K, Willershausen B, Wolf TG (2015): Root 
Canal Morphology and Configuration of 179 Maxillary First Molars by Means of Micro-computed Tomography: An Ex Vivo Study. J Endod 41, 2008-2013

Cachovan G, Schiffner U, Altenhof S, Guentsch A, Pfister W, Eick S (2013): Comparative Antibacterial Efficacies of Hydrodynamic and Ultrasonic Irrigation Systems In Vitro. J Endod 39, 1171-1175

Cameron JA (1995): Factors affecting the clinical efficiency of ultrasonic endodontics: a scanning electron microscopy study. Int Endod J 28, 47-53

Card SJ, Sigurdsson A, Ørstavik D, Trope M (2002): The effectiveness of increased apical enlargement in reducing intracanal bacteria. J Endod 28, 779783

Castelo-Baz P, Martín-Biedma B, Cantatore G, Ruíz-Piñón M, Bahillo J, RivasMundiña B, Varela-Patiño P (2012): In Vitro Comparison of Passive and Continuous Ultrasonic Irrigation in Simulated Lateral Canals of Extracted Teeth. J Endod 38, 688-691

Cengiz T, Aktener BO, Piskin B (1990): Effect of dentinal tubule orientation on the removal of smear layer by root canal irrigants. A scanning electron microscopic study. Int Endod J 23, 163-171

Chow TW (1983): Mechanical effectiveness of root canal irrigation. J Endod $\underline{9}$, 475-479

Cunningham WT, Martin H, Forrest WR (1982): Evaluation of root canal débridement by the endosonic ultrasonic synergistic system. Oral Surg Oral Med Oral Pathol $\underline{53}, 401-404$

de Gregorio C, Estevez R, Cisneros R, Paranjpe A, Cohenca N (2010): Efficacy of Different Irrigation and Activation Systems on the Penetration of Sodium Hypochlorite into Simulated Lateral Canals and up to Working Length: An In Vitro Study. J Endod 36, 1216-1221

DGZMK (2006): Wissenschaftliche Stellungnahme: Die Wurzelkanalspülung. Dtsch Zahnärztl Z 41, 448-449

Drake DR, Wiemann AH, Rivera EM, Walton RE (1994): Bacterial retention in canal walls in vitro: effect of smear layer. J Endod 20, 78-82

Dürr Dental Der neue Vector Paro - Maßstab in Sachen schmerzarmer 
Therapie. Bietigheim o.J. Abrufbar unter

https://www.duerrdental.com/fileadmin/assets/epaper/deu/130305_epaper-

Vector-Paro-DE/index.html [Zugriff am 27.7.2016].

Falk KW, Sedgley CM (2005): The influence of preparation size on the mechanical efficacy of root canal irrigation in vitro. J Endod 31, 742-745

Ferreira FBA, Ferreira AL, Gomes BPFA, Souza-Filho FJ (2004): Resolution of persistent periapical infection by endodontic surgery. Int Endod J 37, 61-69

Friedman S (2002): Prognosis of initial endodontic therapy. Endod Top 2, 59-88 Goode N, Khan S, Eid AA, Niu L, Gosier J, Susin LF, Pashley DH, Tay FR (2013): Wall shear stress effects of different endodontic irrigation techniques and systems. J Dent 41 , 636-641

Gu L, Kim JR, Ling J, Choi KK, Pashley DH, Tay FR (2009): Review of Contemporary Irrigant Agitation Techniques and Devices. J Endod 35, 791-804

Gulabivala K, Patel B, Evans G, Ng Y-L (2005): Effects of mechanical and chemical procedures on root canal surfaces. Endod Top 10, 103-122

Gutarts R, Nusstein J, Reader A, Beck M (2005): In vivo debridement efficacy of ultrasonic irrigation following hand-rotary instrumentation in human mandibular molars. J Endod 31, 166-170

Haapasalo M, Endal U, Zandi H, Coil JM (2005): Eradication of endodontic infection by instrumentation and irrigation solutions. Endod Top 10, 77-102

Halford A, Ohl C-D, Azarpazhooh A, Basrani B, Friedman S, Kishen A (2012): Synergistic Effect of Microbubble Emulsion and Sonic or Ultrasonic Agitation on Endodontic Biofilm in Vitro. J Endod 38, 1530-1534

Harrison AJ, Chivatxaranukul P, Parashos P, Messer HH (2010): The effect of ultrasonically activated irrigation on reduction of Enterococcus faecalis in experimentally infected root canals: Disinfection of infected root canals. Int Endod J 43, 968-977

Hsieh YD, Gau CH, Kung Wu SF, Shen EC, Hsu PW, Fu E (2007): Dynamic recording of irrigating fluid distribution in root canals using thermal image analysis. Int Endod J 40, 11-17

Huffaker SK, Safavi K, Spångberg LSW, Kaufman B (2010): Influence of a 
Passive Sonic Irrigation System on the Elimination of Bacteria from Root Canal Systems: A Clinical Study. J Endod 36, 1315-1318

Jensen SA, Walker TL, Hutter JW, Nicoll BK (1999): Comparison of the cleaning efficacy of passive sonic activation and passive ultrasonic activation after hand instrumentation in molar root canals. J Endod 25, 735-738

Jiang L-M, Verhaagen B, Versluis M, van der Sluis LWM (2010a): Evaluation of a Sonic Device Designed to Activate Irrigant in the Root Canal. J Endod 36, 143-146

Jiang L-M, Verhaagen B, Versluis M, van der Sluis LWM (2010b): Influence of the Oscillation Direction of an Ultrasonic File on the Cleaning Efficacy of Passive Ultrasonic Irrigation. J Endod 36, 1372-1376

Jiang L-M, Verhaagen B, Versluis M, Langedijk J, Wesselink P, van der Sluis LWM (2011): The Influence of the Ultrasonic Intensity on the Cleaning Efficacy of Passive Ultrasonic Irrigation. J Endod 37, 688-692

Jiang L-M, Lak B, Eijsvogels LM, Wesselink P, van der Sluis LWM (2012): Comparison of the Cleaning Efficacy of Different Final Irrigation Techniques. J Endod 38, 838-841

Kahn FH, Rosenberg PA, Gliksberg J (1995): An in vitro evaluation of the irrigating characteristics of ultrasonic and subsonic handpieces and irrigating needles and probes. J Endod 21, 277-280

Kanter V, Weldon E, Nair U, Varella C, Kanter K, Anusavice K, Pileggi R (2011): $A$ quantitative and qualitative analysis of ultrasonic versus sonic endodontic systems on canal cleanliness and obturation. Oral Surg Oral Med Oral Pathol Oral Radiol Endod 112, 809-813

Khademi A, Yazdizadeh M, Feizianfard M (2006): Determination of the Minimum Instrumentation Size for Penetration of Irrigants to the Apical Third of Root Canal Systems. J Endod 32, 417-420

Khambay BS, Walmsley AD (1999): Acoustic microstreaming: detection and measurement around ultrasonic scalers. J Periodontol $\underline{70}, 626-631$

Kishen A, Shi Z, Shrestha A, Neoh KG (2008): An Investigation on the Antibacterial and Antibiofilm Efficacy of Cationic Nanoparticulates for Root 
Canal Disinfection. J Endod 34, 1515-1520

Kishida M, Sato S, Ito K (2004): Effects of a new ultrasonic scaler on fibroblast attachment to root surfaces: a scanning electron microscopy analysis. J Periodontal Res 39, 111-119

Klyn SL, Kirkpatrick TC, Rutledge RE (2010): In Vitro Comparisons of Debris Removal of the EndoActivator System, the F File, Ultrasonic Irrigation, and $\mathrm{NaOCl}$ Irrigation Alone after Hand-rotary Instrumentation in Human Mandibular Molars. J Endod 36, 1367-1371

Komet Dental (2014): Gebrauchsanweisung SF 65. o.O.

Kumar RR, Prakash KH, Yennie K, Cheang P, Khor KA (2005): Synthesis and characterisation of hydroxyapatite nano-rods/whiskers. Key Eng Mater 284, 5962

Lee S-J, Wu M-K, Wesselink PR (2004a): The effectiveness of syringe irrigation and ultrasonics to remove debris from simulated irregularities within prepared root canal walls. Int Endod J 37, 672-678

Lee S-J, Wu M-K, Wesselink PR (2004b): The efficacy of ultrasonic irrigation to remove artificially placed dentine debris from different-sized simulated plastic root canals. Int Endod J 37, 607-612

Liang Y-H, Jiang L-M, Jiang L, Chen X-B, Liu Y-Y, Tian F-C, Bao X-D, Gao X-J, Versluis M, Wu M-K, van der Sluis L (2013): Radiographic Healing after a Root Canal Treatment Performed in Single-rooted Teeth with and without Ultrasonic Activation of the Irrigant: A Randomized Controlled Trial. J Endod 39, 12181225

Lumley PJ, Blunt L, Walmsley AD, Marquis PM (1996): Analysis of the surface cut by sonic files. Endod Dent Traumatol 12, 240-245

Mader CL, Baumgartner JC, Peters DD (1984): Scanning electron microscopic investigation of the smeared layer on root canal walls. J Endod 10, 477-483

Malki M, Verhaagen B, Jiang L-M, Nehme W, Naaman A, Versluis M, Wesselink $P$, van der Sluis L (2012): Irrigant Flow beyond the Insertion Depth of an Ultrasonically Oscillating File in Straight and Curved Root Canals: Visualization and Cleaning Efficacy. J Endod 38, 657-661 
Mancini M, Cerroni L, lorio L, Armellin E, Conte G, Cianconi L (2013): Smear Layer Removal and Canal Cleanliness Using Different Irrigation Systems (EndoActivator, EndoVac, and Passive Ultrasonic Irrigation): Field Emission Scanning Electron Microscopic Evaluation in an In Vitro Study. J Endod 39, $1456-1460$

Martins Justo A, Abreu da Rosa R, Santini MF, Cardoso Ferreira MB, Pereira JR, Húngaro Duarte MA, Reis Só MV (2014): Effectiveness of Final Irrigant Protocols for Debris Removal from Simulated Canal Irregularities. J Endod $\underline{40}$, 2009-2014

McComb D, Smith DC (1975): A preliminary scanning electron microscopic study of root canals after endodontic procedures. J Endod 1, 238-242

Merino A, Estevez R, de Gregorio C, Cohenca N (2013): The effect of different taper preparations on the ability of sonic and passive ultrasonic irrigation to reach the working length in curved canals. Int Endod J $\underline{46}, 427-433$

Michelich VJ, Schuster GS, Pashley DH (1980): Bacterial penetration of human dentin in vitro. J Dent Res 59, 1398-1403

Moghadas L, Narimani T, Shahmoradi M (2012): Antimicrobial activity of a new nanobased endodontic irrigation solution: In vitro study. Dent Hypotheses $\underline{3}$, $142-146$

Mohammadi Z, Shalavi S, Giardino L, Palazzi F, Asgary S (2015): Impact of Ultrasonic Activation on the Effectiveness of Sodium Hypochlorite: A Review. Iran Endod J 10, 216-220

Molven O, Olsen I, Kerekes K (1991): Scanning electron microscopy of bacteria in the apical part of root canals in permanent teeth with periapical lesions. Endod Dent Traumatol 7, 226-229

Mortazavi V, Nahrkhalaji MM, Fathi MH, Mousavi SB, Esfahani BN (2010): Antibacterial effects of sol-gel-derived bioactive glass nanoparticle on aerobic bacteria. J Biomed Mater Res A 94A, 160-168

Moser JB, Heuer MA (1982): Forces and efficacy in endodontic irrigation systems. Oral Surg Oral Med Oral Pathol 53, 425-428

Nair PNR (1987): Light and electron microscopic studies of root canal flora and 
periapical lesions. J Endod 13, 29-39

Neelakantan P, Cheng CQ, Mohanraj R, Sriraman P, Subbarao C, Sharma S (2015): Antibiofilm activity of three irrigation protocols activated by ultrasonic, diode laser or Er:YAG laser in vitro. Int Endod J 48, 602-610

Ng Y-L, Mann V, Gulabivala K (2010): Tooth survival following non-surgical root canal treatment: a systematic review of the literature. Int Endod J 43, 171-189

Ørstavik D, Haapasalo M (1990): Disinfection by endodontic irrigants and dressings of experimentally infected dentinal tubules. Endod Dent Traumatol $\underline{6}$, 142-149

Paqué F, Balmer M, Attin T, Peters OA (2010): Preparation of Oval-shaped Root Canals in Mandibular Molars Using Nickel-Titanium Rotary Instruments: A Micro-computed Tomography Study. J Endod 36, 703-707

Paqué F, Boessler C, Zehnder M (2011): Accumulated hard tissue debris levels in mesial roots of mandibular molars after sequential irrigation steps: Debris reduction. Int Endod J 44, 148-153

Paragliola R, Franco V, Fabiani C, Mazzoni A, Nato F, Tay FR, Breschi L, Grandini S (2010): Final Rinse Optimization: Influence of Different Agitation Protocols. J Endod 36, 282-285

Pashley DH, Michelich V, Kehl T (1981): Dentin permeability: effects of smear layer removal. J Prosthet Dent 46 , 531-537

Pashley DH, Tao L, Boyd L, King GE, Horner JA (1988): Scanning electron microscopy of the substructure of smear layers in human dentine. Arch Oral Biol 33, 265-270

Peciuliene V, Maneliene R, Balcikonyte E, Drukteinis S, Rutkunas V (2008): Microorganisms in root canal infections: a review. Stomatologija 10, 4-9

Ram Z (1977): Effectiveness of root canal irrigation. Oral Surg Oral Med Oral Pathol 44, 306-312

Richman M (1957): The use of ultrasonics in root canal therapy and root resection. J Med 12, 8-12

Rödig T, Bozkurt M, Konietschke F, Hülsmann M (2010a): Comparison of the Vibringe System with Syringe and Passive Ultrasonic Irrigation in Removing 
Debris from Simulated Root Canal Irregularities. J Endod 36, 1410-1413

Rödig T, Döllmann S, Konietschke F, Drebenstedt S, Hülsmann M (2010b): Effectiveness of Different Irrigant Agitation Techniques on Debris and Smear Layer Removal in Curved Root Canals: A Scanning Electron Microscopy Study. J Endod 36, 1983-1987

Rödig T, Sedghi M, Konietschke F, Lange K, Ziebolz D, Hülsmann M (2010c): Efficacy of syringe irrigation, RinsEndo and passive ultrasonic irrigation in removing debris from irregularities in root canals with different apical sizes: Removal of debris. Int Endod J 43, 581-589

Rödig T, Hirschleb M, Zapf A, Hülsmann M (2011): Comparison of ultrasonic irrigation and RinsEndo for the removal of calcium hydroxide and Ledermix paste from root canals: Removal of intracanal dressings. Int Endod J 44, 11551161

Rödig T, Kupis J, Konietschke F, Dullin C, Drebenstedt S, Hülsmann M (2014): Comparison of hand and rotary instrumentation for removing gutta-percha from previously treated curved root canals: a microcomputed tomography study. Int Endod J 47, 173-182

Rollison S, Barnett F, Stevens RH (2002): Efficacy of bacterial removal from instrumented root canals in vitro related to instrumentation technique and size. Oral Surg Oral Med Oral Pathol Oral Radiol Endod 94, 366-371

Roy RA, Ahmad M, Crum LA (1994): Physical mechanisms governing the hydrodynamic response of an oscillating ultrasonic file. Int Endod J 27, 197-207 Sabins RA, Johnson JD, Hellstein JW (2003): A comparison of the cleaning efficacy of short-term sonic and ultrasonic passive irrigation after hand instrumentation in molar root canals. J Endod 29, 674-678

Sáinz-Pardo M, Estevez R, Pablo ÓV de, Rossi-Fedele G, Cisneros R (2014): Root Canal Penetration of a Sodium Hypochlorite Mixture Using Sonic or Ultrasonic Activation. Braz Dent J 25, 489-493

Samiei M, Farjami A, Dizaj SM, Lotfipour F (2016): Nanoparticles for antimicrobial purposes in Endodontics: A systematic review of in vitro studies. Mater Sci Eng C Mater Biol Appl 58, 1269-1278 
Schäfer E (2002): Effect of physical vapor deposition on cutting efficiency of nickel-titanium files. J Endod 28, 800-802

Sedgley C, Applegate B, Nagel A, Hall D (2004): Real-time imaging and quantification of bioluminescent bacteria in root canals in vitro. J Endod 30, 893-898

Sedgley CM, Nagel AC, Hall D, Applegate B (2005): Influence of irrigant needle depth in removing bioluminescent bacteria inoculated into instrumented root canals using real-time imaging in vitro. Int Endod J 38, 97-104

Shrestha A, Kishen A (2014): Antibacterial Efficacy of Photosensitizer Functionalized Biopolymeric Nanoparticles in the Presence of Tissue Inhibitors in Root Canal. J Endod 40, 566-570

Shrestha A, Fong S-W, Khoo B-C, Kishen A (2009): Delivery of Antibacterial Nanoparticles into Dentinal Tubules Using High-intensity Focused Ultrasound. J Endod 35, 1028-1033

Spratt DA, Pratten J, Wilson M, Gulabivala K (2001): An in vitro evaluation of the antimicrobial efficacy of irrigants on biofilms of root canal isolates. Int Endod J 34, 300-307

Srirekha A, Rashmi K, Hegde J, Lekha S, Rupali K, Reshmi G (2012): An In Vitro Evaluation of Passive Ultrasonic Agitation of Different Irrigants on Smear Layer Removal After Post Space Preparation: A Scanning Electron Microscopic Study. J Indian Prosthodont Soc 13, 240-246

Svensäter G, Bergenholtz G (2004): Biofilms in endodontic infections. Endod Top 9 , 27-36

Tay FR, Gu L, Schoeffel GJ, Wimmer C, Susin L, Zhang K, Arun SN, Kim J, Looney SW, Pashley DH (2010): Effect of Vapor Lock on Root Canal Debridement by Using a Side-vented Needle for Positive-pressure Irrigant Delivery. J Endod 36, 745-750

Taylor JK, Jeansonne BG, Lemon RR (1997): Coronal leakage: effects of smear layer, obturation technique, and sealer. J Endod 23, 508-512

van der Sluis LWM, Wu M-K, Wesselink PR (2005a): A comparison between a smooth wire and a K-file in removing artificially placed dentine debris from root 
canals in resin blocks during ultrasonic irrigation. Int Endod J 38, 593-596

van der Sluis LWM, Wu M-K, Wesselink PR (2005b): The efficacy of ultrasonic irrigation to remove artificially placed dentine debris from human root canals prepared using instruments of varying taper. Int Endod J 38, 764-768

van der Sluis LWM, Gambarini G, Wu MK, Wesselink PR (2006a): The influence of volume, type of irrigant and flushing method on removing artificially placed dentine debris from the apical root canal during passive ultrasonic irrigation. Int Endod J 39, 472-476

van der Sluis LWM, Gambarini G, Wu MK, Wesselink PR (2006b): The influence of volume, type of irrigant and flushing method on removing artificially placed dentine debris from the apical root canal during passive ultrasonic irrigation. Int Endod J 39, 472-476

van der Sluis LWM, Versluis M, Wu MK, Wesselink PR (2007a): Passive ultrasonic irrigation of the root canal: a review of the literature. Int Endod J $\underline{40}$, $415-426$

van der Sluis LWM, Wu MK, Wesselink PR (2007b): The evaluation of removal of calcium hydroxide paste from an artificial standardized groove in the apical root canal using different irrigation methodologies. Int Endod J 40, 52-57

van der Sluis LWM, Vogels MPJM, Verhaagen B, Macedo R, Wesselink PR (2010): Study on the Influence of Refreshment/Activation Cycles and Irrigants on Mechanical Cleaning Efficiency During Ultrasonic Activation of the Irrigant. J Endod 36, 737-740

Vinhorte MC, Suzuki EH, de Carvalho MS, Marques AAF, Sponchiado Júnior EC, Garcia L da FR (2014): Effect of passive ultrasonic agitation during final irrigation on cleaning capacity of hybrid instrumentation. Restor Dent Endod 39, 104

Violich DR, Chandler NP (2010): The smear layer in endodontics - a review: Smear layer in endodontics. Int Endod J 43, 2-15

Walmsley AD, Lea SC, Felver B, King DC, Price GJ (2013): Mapping cavitation activity around dental ultrasonic tips. Clin Oral Investig 17, 1227-1234

Weller RN, Brady JM, Bernier WE (1980): Efficacy of ultrasonic cleaning. J 
Endod 6 , 740-743

Wu C, Chang J, Fan W (2012): Bioactive mesoporous calcium-silicate nanoparticles with excellent mineralization ability, osteostimulation, drugdelivery and antibacterial properties for filling apex roots of teeth. J Mater Chem 22, 16801-16809

Wu D, Fan W, Kishen A, Gutmann JL, Fan B (2014): Evaluation of the Antibacterial Efficacy of Silver Nanoparticles against Enterococcus faecalis Biofilm. J Endod 40, 285-290

Wu MK, Wesselink PR (1995): Efficacy of three techniques in cleaning the apical portion of curved root canals. Oral Surg Oral Med Oral Pathol Oral Radiol Endod 79, 492-496

Yamada RS, Armas A, Goldman M, Lin PS (1983): A scanning electron microscopic comparison of a high volume final flush with several irrigating solutions: Part 3. J Endod 9, 137-142 


\section{Materialliste}

\begin{tabular}{|c|c|}
\hline Produkt & Firma \\
\hline Diamantschleifkörper & Komet, Lemgo, Deutschland \\
\hline Diamantierter Schallaufsatz & KaVo, Biberach/Riß, Deutschland \\
\hline EDTA $(17 \%)$ & $\begin{array}{l}\text { Lege artis Pharma, Dettenhausen, } \\
\text { Deutschland }\end{array}$ \\
\hline Endo IT Motor & VDW GmbH, München, Deutschland \\
\hline Fingerspreader & VDW GmbH, München, Deutschland \\
\hline Gates-Glidden Bohrer Größe II und III & Komet, Lemgo, Deutschland \\
\hline $\begin{array}{l}\text { Guttapercha-Stifte Größe 40/.02 \& } \\
20 / .02\end{array}$ & VDW GmbH, München, Deutschland \\
\hline IrriSafe Ultraschallspitze IRR 20-21 & Acteon, Mettmann, Deutschland \\
\hline Kamera moticam 2300 & Motic, Wetzlar, Deutschland \\
\hline Kunststoffrohr & Alt-intech, Neresheim, Deutschland \\
\hline $\mathrm{NaOCl}(3 \%)$ & Hedinger, Stuttgart, Deutschland \\
\hline Mikroskop ,OPMI pico’ & Carl Zeiss, Jena, Deutschland \\
\hline Mikroskop Variophot & Wild Leitz, Wetzlar, Deutschland \\
\hline Mtwo-Feilen bis 40/.04 & VDW GmbH, München, Deutschland \\
\hline Papierspitzen & $\begin{array}{l}\text { Multident Dental, Oldenburg, } \\
\text { Deutschland }\end{array}$ \\
\hline Peripherywachs & $\begin{array}{l}\text { Sigma Dental, Handewitt, } \\
\text { Deutschland }\end{array}$ \\
\hline Rosenbohrer & Komet, Lemgo, Deutschland \\
\hline Scaler & HLW, Wernberg-Köblitz, Deutschland \\
\hline
\end{tabular}




\begin{tabular}{|l|l|}
\hline SF 65 & Komet, Lemgo, Deutschland \\
\hline Silaplast Futur & Detax, Ettlingen, Deutschland \\
\hline SONICflex-Handstück 2003 & KaVo, Biberach/Riß, Deutschland \\
\hline Spritze 5ml & B. Braun, Melsungen, Deutschland \\
\hline Spülnadel Endoneedle & Vedefar, Dilbeek, Belgien \\
\hline Trennscheibe & Horico, Berlin, Deutschland \\
\hline VDW Ultra - Dental ultrasonic & VDW GmbH, München, Deutschland \\
\hline generator & $\begin{array}{l}\text { Dürr Dental, Bietigheim-Bissingen, } \\
\text { Deutschland }\end{array}$ \\
\hline Vector polish & Henry Schein, Langen, Deutschland \\
\hline Wachsmesser & NSK, Tochigi, Japan \\
\hline Winkelstück (rot/grün) & GABA, Lörrach, Deutschland \\
\hline Zahnbürste &
\end{tabular}

Tabelle 6: Materialliste 


\section{Danksagung}

Mein besonderer Dank gilt Herrn Prof. Dr. med. dent. Michael Hülsmann für die freundliche Überlassung des Dissertationsthemas. Die andauernde, zuverlässige und stets motivierende Betreuung und die geduldige Korrektur dieser Arbeit trugen maßgeblich zu dem erfolgreichen Gelingen bei.

Für die vielen Stunden während der praktischen Versuche möchte ich mich auch bei Anne Reus bedanken.

An dieser Stelle möchte ich mich bei allen bedanken, die mich in den vergangenen Monaten unterstützt und mich auf meinem Weg begleitet haben. 